Document downloaded from:

http://hdl.handle.net/10251/151317

This paper must be cited as:

Navarro, I.; Yepes, V.; Martí, J. (2020). Sustainability assessment of concrete bridge deck designs in coastal environments using neutrosophic criteria weights. Structure and Infrastructure Engineering. 16(7):949-967. https://doi.org/10.1080/15732479.2019.1676791

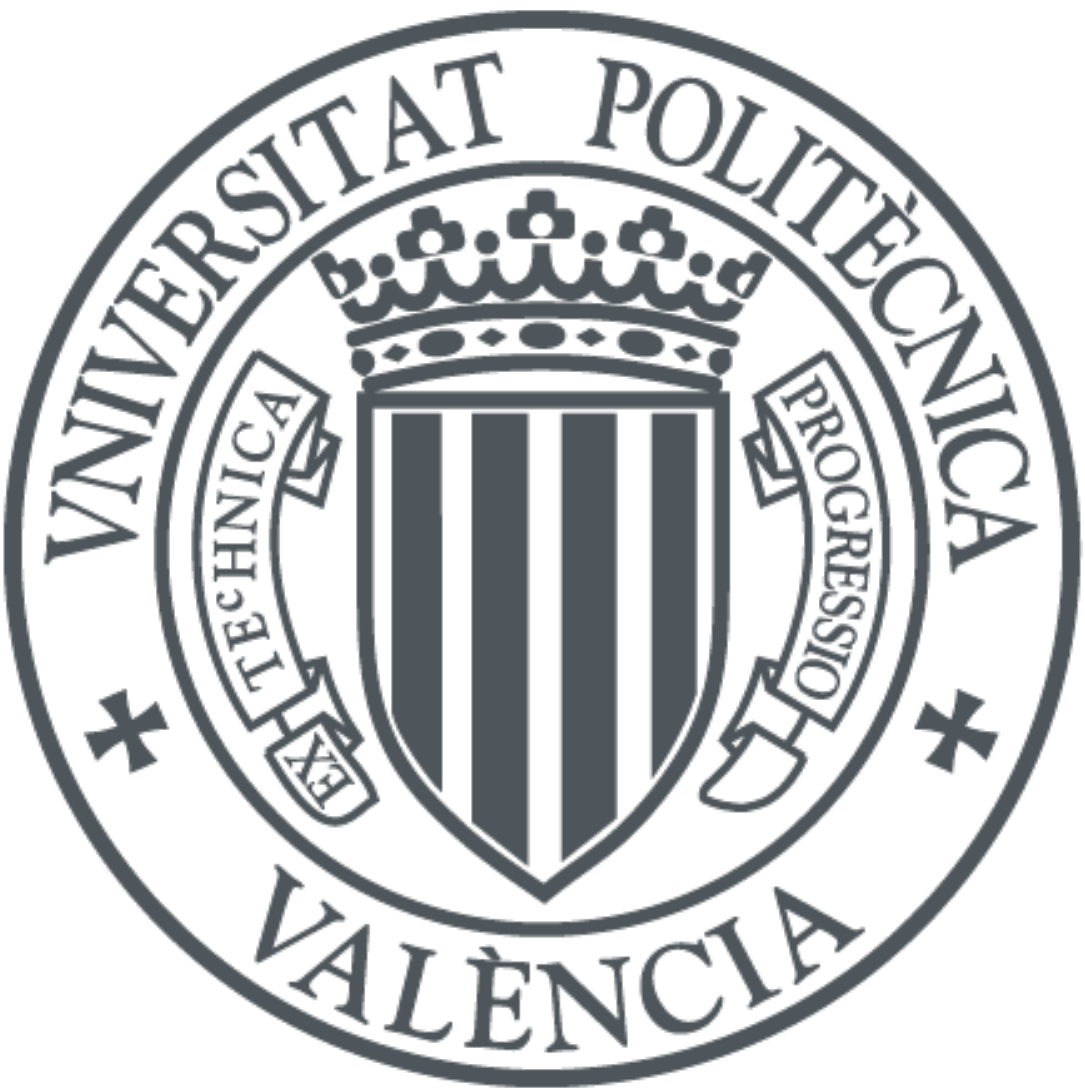

The final publication is available at

https://doi.org/10.1080/15732479.2019.1676791

Copyright Taylor \& Francis

Additional Information

"This is an Accepted Manuscript of an article published by Taylor \& Francis in Structure and Infrastructure Engineering on 02/07/2020, available online:

https://doi.org/10.1080/15732479.2019.1676791." 
Sustainability assessment of concrete bridge deck designs in coastal environments using neutrosophic criteria weights

Ignacio J. Navarro ${ }^{\mathrm{a}}$, Víctor Yepes ${ }^{\mathrm{b}^{*}}$, José V. Martíb

${ }^{a}$ Dept. of Construction Engineering, Universitat Politècnica de València, 46022

Valencia, Spain

${ }^{b}$ Institute of Concrete Science and Technology (ICITECH), Universitat Politècnica de València, 46022 Valencia, Spain

*Corresponding author: vyepesp@cst.upv.es (V. Yepes) 


\title{
Sustainability assessment of concrete bridge deck designs in coastal environments using neutrosophic criteria weights
}

\begin{abstract}
Essential infrastructures such as bridges are designed to provide a long-lasting and intergenerational functionality. In those cases, sustainability becomes of paramount importance when the infrastructure is exposed to aggressive environments which can jeopardize their durability and lead to significant maintenance demands. The assessment of sustainability is however often complex and uncertain. The present study assesses the sustainability performance of 16 alternative designs of a concrete bridge deck in a coastal environment on the basis of a neutrosophic group Analytic Hierarchy Process (AHP). The use of neutrosophic logic in the field of multi-criteria decision-making, as a generalisation of the widely used fuzzy logic, allows for a proper capture of the vagueness and uncertainties of the judgements emitted by the decision makers. TOPSIS technique is then used to aggregate the different sustainability criteria. From the results, it is derived that only the simultaneous consideration of the economic, environmental and social life cycle impacts of a design shall lead to adequate sustainable designs. Choices made on the basis of the optimality of a design in only some of the sustainability pillars will lead to erroneous conclusions. The use of concrete with silica fume has resulted in a sustainability performance $46.3 \%$ better than conventional concrete designs.
\end{abstract}

Keywords: sustainable design; chloride corrosion; neutrosophic AHP; preventive maintenance; multi-criteria decision-making; life cycle assessment

\section{Introduction}

As developed countries have been placing greater emphasis on the conservation of infrastructures, durability has become a key issue in structural design. During the last decades, significant efforts have been made to optimise the maintenance strategies of structures in terms of their life cycle costs, paying special attention to bridge structures (Sabatino, Frangopol, \& Dong, 2016; Barone \& Frangopol, 2014). Eamon, Jensen, Grace, and Shi (2012) compare the life cycle costs of different reinforcement materials used in bridge deck designs. Safi, Sundquist, and Karoumi (2015) introduce a life cycle cost 
assessment technique to help agencies in the exploitation of their Bridge Management Systems through fair tendering processes. Efforts have also been conducted on the optimisation of maintenance strategies and on the selection of the most cost-efficient corrosion preventive design of concrete (Navarro, Martí, \& Yepes, 2018a; Sajedi and Huang, 2019) and steel bridges (Cope, Bai, Samdariya, \& Labi, 2013; Kere and Huang, 2019). In general terms, studies conclude that the maintenance phase of bridges is an essential source of impacts during their life cycle, and that the optimisation of maintenance is therefore crucial to reduce such impacts.

However, the life cycle cost optimisation of structures is currently not enough to meet the increasing environmental and social demands of the $21^{\text {st }}$ century world. Since its definition in 1987, sustainability has called for a paradigmatic shift in the way structural design and maintenance are optimised: it is now expected that from the design stage, infrastructure designers will simultaneously take into account the effects of economic, social and environmental decisions. Consequently, research has been conducted to include environmental and social considerations in the design of infrastructures, taking into account different aspects such as embodied energy (Martí, García-Segura, \& Yepes, 2016), greenhouse gas emissions (García-Segura, Yepes, Frangopol, \& Dong, 2017; García-Segura \& Yepes, 2016), or social impacts (Navarro, Yepes, \& Martí, 2018b; Sierra, Yepes, García-Segura, \& Pellicer, 2018) derived from construction activities. Sustainable design and management of infrastructures are complex problems involving multiple and conflicting criteria. During the last few years, Multi-Criteria DecisionMaking (MCDM) techniques have been used to assess the sustainability of infrastructures, such as bridges (Gervásio, \& Da Silva, 2012; Yepes, García-Segura, \& Moreno-Jiménez, 2015), buildings (Mosalam, Alibrandi, Lee, \& Armengou, 2018; 
Invidiata, Lavagna, \& Ghisi, 2018), or hydraulic infrastructures (De la Fuente, Pons, Josa, \& Aguado, 2016; Tahmasebi \& Yazdandoost, 2018), among others.

Different MCDM methodologies have been used in the existing literature for such sustainability-oriented infrastructure assessments, being the Simple Additive Weighting (SAW) technique the most widely used one (Rashidi, Samali, \& Sharafi, 2016; Jakiel \& Fabianowsky, 2015). The popularity of such technique is based on its ease of use. However, as it can only handle with maximizing, positive defined criteria, during the past years other MCDM methods have been preferred for sustainability assessments, such as TOPSIS (Guzmán-Sánchez, Jato-Espino, Bombillo, \& Diaz-Sarachaga, 2018) or ELECTRE (Heravi, Fathi, \& Faeghi, 2017).

TOPSIS (Technique for Order of Preference by Similarity to Ideal Solution) is an MCDM method that allows to rank different alternatives taking into account the fact that the most desirable solution should have the shortest Euclidean distance to the positive ideal solution, and the longest distance to the less preferred one (Penadés-Plà, GarcíaSegura, Martí, \& Yepes, 2016). The ideal point is constructed from the best performance scores exhibited for each criterion by any alternative, while the less preferred point is derived from the worst performances. This technique is meant to allow for the simultaneous consideration of qualitative and quantitative criteria in the assessment. After SAW, TOPSIS method is the second most popular technique used to deal with MCDM problems (Zavadskas, Mardani, Turskis, Jusoh, \& Nor, 2016).

The resolution of such MCDM problems in the field of sustainability is usually based on the subjective judgments of several decision makers (DM). To derive the relative relevance of each criterion involved in MCDM assessments related to infrastructure projects based on individual preferences of DMs, Analytic Hierarchy Process (AHP) has been widely used (Ali, Aslam, \& Mirza, 2015; Pryn, Cornet, \& Salling, 2015). AHP 
technique presumes the judgements to be both precise and certain. However, as the complexity of an assessment increases, the ability of individuals to make meaningful and accurate judgments diminishes to the point where both attributes become almost exclusive (Zadeh, 1973). Therefore, traditional AHP, as originally defined by Saaty (Saaty, 1980), has been the subject of strong criticism for not being able to reflect the complex and diffuse nature of human thought (Radwan, Senousy, \& Riad, 2016).

In an attempt to handle the non-probabilistic uncertainties associated with human cognitive information in decision-making problems, the fuzzy sets theory (Zadeh, 1965) has been applied to derive criteria weights using an AHP approach in the field of construction industry (Penadés-Plà et al., 2016), assessing different aspects ranging from pavement maintenance (Moazami, Behbahani, \& Muniandy, 2011) or bridges design (García-Segura, Penadés-Plà, \& Yepes, 2018) to the selection of construction projects (Prascevic \& Prascevic, 2017). MCDM based on fuzzy logic assigns to the emitted judgements a so-called membership grade, which represents to what extent the information provided by the DM is certain or not. Such grade lies between 0 and 1. Fuzzy sets theory successfully incorporates the vagueness of human thinking into mathematical modelling, although only to a certain extent, as it cannot deal with more complex contexts involving incomplete information.

Fuzzy sets theory was further generalized by Atanassov (1986), who introduced the Intuitionistic fuzzy sets (IFSs). IFSs complement the membership grade of fuzzy elements with a non-membership grade. Both grades are dependent on each other, and their sum cannot be greater than 1. Fuzzy sets are considered as a particular case of IFSs where the non-membership grade is equal to zero. IFSs have been applied in a variety of fields, such as the sustainability evaluation of energy technologies (Abdullah, \& Najib, 2016), supplier selection (Bykzkan \& Ger, 2017), or landfill site selection (Kahraman, 
Cebi, Onar, \& Oztaysi, 2018), among others. However, the dependency between grades associated to IFSs does not allow to mathematically model more complex aspects related to nonprobabilistic uncertainties, such as information inconsistencies or paradoxes.

Neutrosophic sets (NSs) theory has been recently introduced by Smarandache (1999) as a means to fill the modeling gaps still left with the IFSs by further generalizing the IFSs theory. In neutrosophic logic, elements are described by means of three independent properties, namely, indeterminacy, truth and falsity, thus allowing dealing with most cases of linguistic vagueness, inconsistencies and even with paradoxical statements. Although introduced in 1999, it has been only in very recent years that NSs theory has been developed from a practical point of view to deal with real scientific and engineering applications. Consequently, during the last few years, NSs theory has been applied to assess decision making problems, dealing with aspects such as supplier selection (Abdel-Basset, Manogaran, Mohamed, \& Chilamkurti, 2018; Peng, Wang, \& Yang, 2017), company investment strategies (Liu \& Liu, 2018) or power technology selection (Pamucar, Badi, Sanja, \& Obradovic, 2018).

The construction sector is considered to be one of the main stressors of the economy and environment of a region, but it can contribute in a similar way to its social and economic development. Therefore, proper design and management of infrastructures becomes essential to ensure the sustainability of a country. Given the significant impact that the weightings of the criteria can have on the outcome of MCDM processes, it is essential to capture the maximum information underlying the subjective judgments of DMs in the evaluation of the infrastructures. Although NSs provide a powerful tool for this purpose (Bolturk \& Kahraman, 2018), to the best knowledge of the authors, it has not yet been applied to the sustainability assessment of infrastructures. The present paper provides a neutrosophic-based MCDM methodology to be integrated with the ISO- 
standarised life cycle assessment procedure (ISO, 2006) applied to the evaluation of the sustainability of structures. In particular, such methodology is applied to assess the sustainability of different design alternatives and maintenance strategies of a concrete bridge in an aggressive environment using TOPSIS technique.

\section{Materials and methods}

\subsection{Preliminaries on Neutrosophic sets}

In this section, some important definitions pertaining to neutrosophic sets theory are introduced, which are required for an adequate understanding of the subsequent sections of the present paper.

Definition 1. (Smarandache, 1999; Ye, 2013) Let $X$ be a non-empty space of points, where $x \in X$. A single-valued neutrosophic set $A$ in $X$ is defined as:

$$
A=\left\{\left\langle x, T_{A}(x), I_{A}(x), F_{A}(x)\right\rangle \mid x \in X\right\}
$$

where $T_{A}(x), F_{A}(x), I_{A}(x) \in[0,1]$ denote the truth, falsity and the indeterminacy membership degree of the element $x \in X$, respectively. The membership functions are independent and satisfy that:

$$
0<T_{A}(x)+I_{A}(x)+F_{A}(x)<3
$$

Definition 2. (Deli \& Şubaş, 2017) A single-valued triangular neutrosophic number $\bar{a}=\left\langle\left(a_{1}, a_{2}, a_{3}\right) ; t_{\bar{a}}, i_{\bar{a}}, f_{\bar{a}}\right\rangle$ is defined as a neutrosophic number on the real number set, whose truth, indeterminacy and falsity membership functions are respectively defined as follows:

$$
\mu_{\bar{a}}(x)=\left\{\begin{array}{cc}
\frac{(x-a)}{(b-a)} \cdot t_{\bar{a}}, & \text { for } a \leq x<b \\
\frac{(c-x)}{(c-b)} \cdot t_{\bar{a}}, & \text { for } b \leq x \leq c \\
0, & \text { otherwise }
\end{array}\right.
$$




$$
\begin{aligned}
& v_{\bar{a}}(x)= \begin{cases}\frac{\left(b-x+i_{\bar{a}} \cdot(x-a)\right)}{(b-a)}, & \text { for } a \leq x<b \\
\frac{\left(x-b+i_{\bar{a}} \cdot(c-x)\right)}{(c-b)}, & \text { for } b \leq x \leq c \\
0, \quad \text { otherwise }\end{cases} \\
& \lambda_{\bar{a}}(x)= \begin{cases}\frac{\left(b-x+f_{\bar{a}} \cdot(x-a)\right)}{(b-a)}, & \text { for } a \leq x<b \\
\frac{\left(x-b+f_{\bar{a}} \cdot(c-x)\right)}{(c-b)}, & \text { for } b \leq x \leq c \\
0, & \text { otherwise }\end{cases}
\end{aligned}
$$

Definition 3. (Liang, Wang, \& Zhang, 2018; Ye, 2017) Let $\bar{a}=\left\langle\left(a_{1}, a_{2}, a_{3}\right) ; t_{\bar{a}}, i_{\bar{a}}, f_{\bar{a}}\right\rangle$ and $\bar{b}=\left\langle\left(b_{1}, b_{2}, b_{3}\right) ; t_{\bar{b}}, i \bar{b}, f_{\bar{b}}\right\rangle$ be two single-valued triangular neutrosophic numbers. Let $k$ be a real, positive number. Then, the basic arithmetic operations for neutrosophic numbers, based on Kolmogorov's probability axioms, are defined as:

$$
\begin{aligned}
& k \bar{a}=\left\langle\left(k a_{1}, k a_{2}, k a_{3}\right) ; 1-\left(1-t_{\bar{a}}\right)^{k},\left(i_{\bar{a}}\right)^{k},\left(f_{\bar{a}}\right)^{k}\right\rangle \\
& \bar{a}^{k}=\left\langle\left(a_{1}{ }^{k}, a_{2}{ }^{k}, a_{3}{ }^{k}\right) ;\left(t_{\bar{a}}\right)^{k}, 1-\left(1-i_{\bar{a}}\right)^{k}, 1-\left(1-f_{\bar{a}}\right)^{k}\right\rangle \\
& \bar{a}+\bar{b}=\left\langle\left(a_{1}+b_{1}, a_{2}+b_{2}, a_{3}+b_{3}\right) ; t_{\bar{a}}+t_{\bar{b}}-t_{\bar{a}} t_{\bar{b}}, i_{\bar{a}} i_{\bar{b}}, f_{\bar{a}} f_{\bar{b}}\right\rangle \\
& \bar{a} \times \bar{b}=\left\langle\left(a_{1} b_{1}, a_{2} b_{2}, a_{3} b_{3}\right) ; t_{\bar{a}} t_{\bar{b}}, i_{\bar{a}}+i_{\bar{b}}-i_{\bar{a}} i_{\bar{b}}, f_{\bar{a}}+f_{\bar{b}}-f_{\bar{a}} f_{\bar{b}}\right\rangle \\
& \bar{a} \div \bar{b}=\left\langle\left(\frac{a_{1}}{b_{3}}, \frac{a_{2}}{b_{2}}, \frac{a_{3}}{b_{1}}\right) ; \frac{t_{\bar{a}}}{t_{\bar{b}}}, \frac{i_{\bar{a}}-i_{\bar{b}}}{1-i_{\bar{b}}}, \frac{f_{\bar{a}}-f_{\bar{b}}}{1-f_{\bar{b}}}\right\rangle \\
& \text { valid if } t_{\bar{a}} \leq t_{\bar{b}}, i_{\bar{a}} \geq i_{\bar{b}}, f_{\bar{a}} \geq f_{\bar{b}}, t_{\bar{b}} \neq 0, i_{\bar{b}}, f_{\bar{b}} \neq 1
\end{aligned}
$$

\subsection{Neutrosophic extension of the analytical hierarchy process}

AHP is a well-known decision assessment technique where DMs are required to compare two elements belonging to the same hierarchy level with each other. Such comparison is based on the Saaty's fundamental scale (Saaty, 1980), that expresses how much more important one element is with respect to another one. Consequently, when $\mathrm{n}$ elements are compared, the resulting pairwise comparison matrix $A=\left\{a_{i j}\right\}$ is square and reciprocal, i.e. $a_{i j}=1 / a_{j i} \forall i, j \in\{1, \ldots, n\}$. This section presents a neutrosophic extension of 
the traditional scalar (crisp) AHP technique. The steps of the methodology are presented in Figure 1.
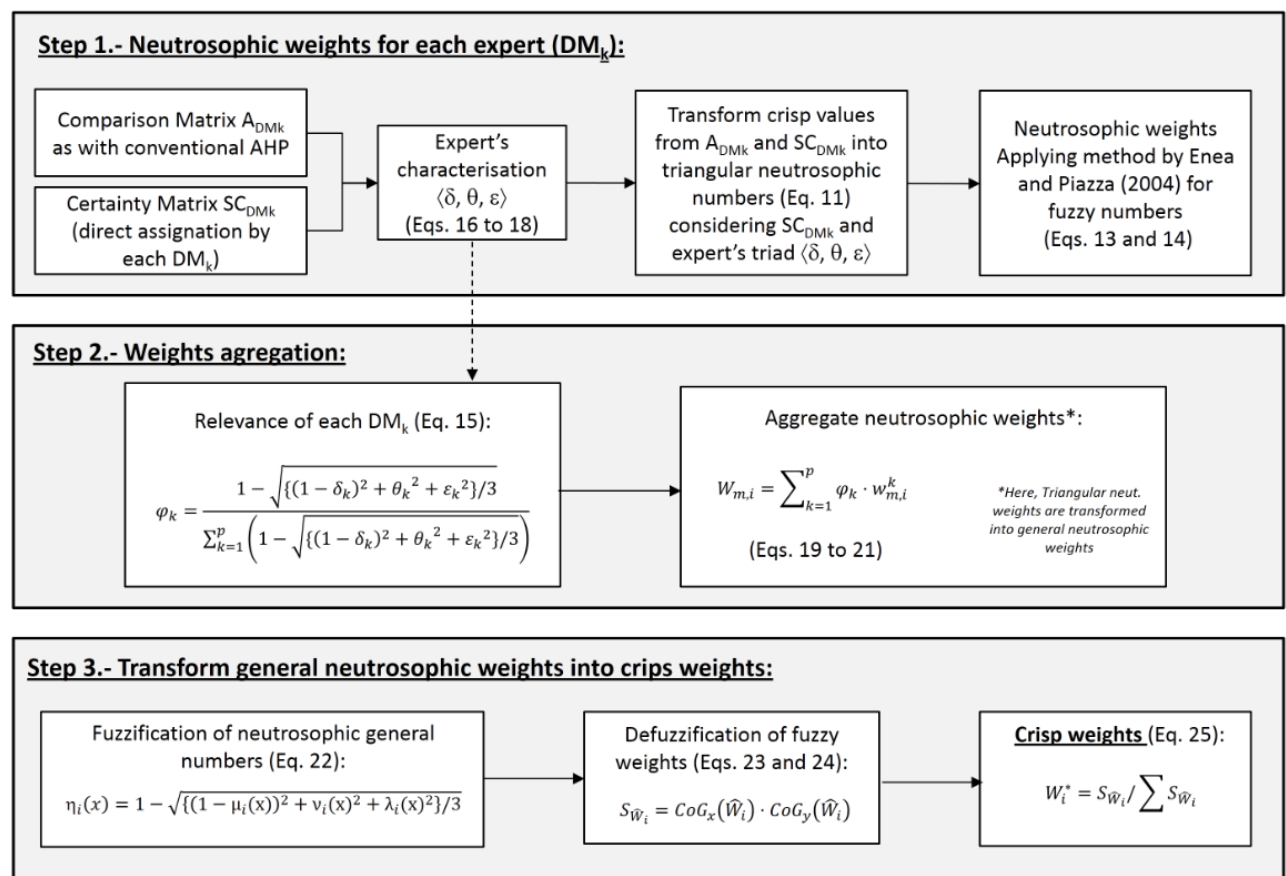

Figure 1. Steps of the group neutrosophic AHP methodology

\subsubsection{Neutrosophic AHP comparison matrix}

To reflect the vagueness of the judgements emitted by the DMs, triangular neutrosophic numbers (TNN) are considered. Let $\bar{A}=\left\{\bar{a}_{i j}\right\}$ represent the neutrosophic pairwise comparison matrix of a DM for n elements with $\bar{a}_{i j}=\left\langle\left(l_{i j}, m_{i j}, u_{i j}\right) ; t_{i j}, i_{i j}, f_{i j}\right\rangle \forall i, j \in\{1, \ldots, n\}$. The reciprocal elements are defined as $\bar{a}_{j i}=1 / \bar{a}_{i j}=\left\langle\left(1 / u_{i j}, 1 / m_{i j}, 1 / l_{i j}\right) ; t_{i j}, i_{i j}, f_{i j}\right\rangle \forall i, j \in\{1, \ldots, n\}$ (Abdel-Basset, Manogaran, Mohamed, \& Chilamkurti, 2018). For the diagonal elements of $\overline{\mathrm{A}}$ it is valid that $\bar{a}_{i i}=\langle(1,1,1) ; 0,0,0\rangle \forall i \in\{1, \ldots, n\}$.

The values $\left(l_{i j}, m_{i j}, u_{i j}\right)$ of every judgement are defined according to Saaty's fundamental scale, and range therefore from $1 / 9$ to 9 . The center values $m_{i j}$ correspond to the judgments emitted by the DM. These are the values that the conventional crisp AHP technique would consider to derive the weights of each element. Here, the center values $\mathrm{m}_{\mathrm{ij}}$ are also required to satisfy the consistency check so as defined by Saaty (1980). The 
lower and upper bounds $\left(l_{i j}, u_{i j}\right)$ are dependent on the certainty $S C_{i j}$ that the DM has declared in relation to his/her statement $\mathrm{a}_{\mathrm{ij}}$, and are calculated as:

$$
l_{i j}=m_{i j}-\Delta V_{i j} ; u_{i j}=m_{i j}+\Delta V_{i j}
$$

where $\Delta V_{i j}$ is the number of steps in the Saaty's scale between the center value $\mathrm{m}_{\mathrm{ij}}$ and the corresponding extremes (García-Segura et al., 2018). Table 1 shows how $\Delta V_{i j}$ is defined here, depending on the certainty $S C_{i j}$ verbally expressed by the DM, which can range from 0 to $100 \%$.

\begin{tabular}{cc}
\hline $\begin{array}{c}\text { Uncertainty in } \\
\text { judgement } \mathrm{a}_{\mathrm{ij}} \\
\left(\mathrm{SC}_{\mathrm{ij}}\right)\end{array}$ & $\begin{array}{c}\text { Steps in Saaty's } \\
\text { scale }\left(\Delta \mathrm{V}_{\mathrm{ij}}\right)\end{array}$ \\
\hline $\mathrm{SC}_{\mathrm{ij}}=1$ & 0 \\
$0.8 \leq \mathrm{SC}_{\mathrm{ij}}<1$ & 1 \\
$0.6 \leq \mathrm{SC}_{\mathrm{ij}}<0.8$ & 2 \\
$0.4 \leq \mathrm{SC}_{\mathrm{ij}}<0.6$ & 3 \\
$0.2 \leq \mathrm{SC}_{\mathrm{ij}}<0.4$ & 4 \\
$0<\mathrm{SC}_{\mathrm{ij}}<0.2$ & 5 \\
$\mathrm{SC}_{\mathrm{ij}}=0$ & 6 \\
\hline Table 1. Range of triangular numbers in relation to expressed uncertainty
\end{tabular}

\subsubsection{Neutrosophic weights}

According to the conventional AHP technique, the weights of each element are calculated using the eigenvalue method. The weights are then obtained as the normalised components of the eigenvector associated to the largest eigenvalue of the comparison matrix. A rigorous calculation of eigenvalues and eigenvectors in a fuzzy and, by extension, neutrosophic environment is neither evident nor practical (Dubois, 2011). Buckley (1985) introduced an alternative weight evaluation procedure for fuzzy comparison matrices based on the geometric mean method, which has been widely used for fuzzy AHP ever since (Tesfamariam \& Sadiq, 2006; Cebeci, 2009). On the basis of the neutrosophic arithmetic, the establishment of which has been recently completed with the introduction of the division operation for neutrosophic sets by Ye (2017), a neutrosophic extension of Buckley's method is proposed here: 


$$
\bar{w}_{i}=\frac{\left(\prod_{j=1}^{n} \bar{a}_{i j}\right)^{1 / n}}{\sum_{i=1}^{n}\left(\prod_{j=1}^{n} \bar{a}_{i j}\right)^{1 / n}}
$$

where $\bar{w}_{i}$ is the triangular neutrosophic weight of element $i, n$ is the number of elements to be compared, and $\bar{a}_{i j}$ is the neutrosophic comparison value between elements $i$ and $j$. However, as originally defined, the normalisation procedure of Buckley's method has been shown to be incorrect if the fuzzy AHP matrices are defined according to Saaty's scale, as it results in fuzzy weights with unreasonably high and asymmetrical uncertainty ranges (Wang \& Elhag 2006). Enea and Piazza (2004) suggested a method to derive an adequate constrained fuzziness range of weights using a scalar mathematical programming model. The method consists in defining the lower (upper) bound of the fuzzy weight of an element as the lowest (greatest) weight that can be obtained by varying each element of the comparison matrix within its respective bounds. An extension of the fuzzy method by Enea and Piazza (2004) is proposed in the present study to derive constrained truth, falsity and indeterminacy ranges of the resulting neutrosophic weights. So, the upper and lower bounds of the neutrosophic weights are obtained through following scalar mathematical programming models:

$$
w_{l, i}=\min \left[\frac{\left(\prod_{j=1}^{n} a_{i j}\right)^{1 / n}}{\sum_{k=1}^{n}\left(\prod_{j=1}^{n} a_{k j}\right)^{1 / n}}\right]
$$

subject to:

$$
\begin{gathered}
a_{k j} \in\left[l_{k j}, u_{k j}\right] \quad \forall j>k \\
a_{j k}=1 / a_{k j} \quad \forall j<k \\
a_{j j}=1
\end{gathered}
$$

and 


$$
w_{u, i}=\max \left[\frac{\left(\prod_{j=1}^{n} a_{i j}\right)^{1 / n}}{\sum_{k=1}^{n}\left(\prod_{j=1}^{n} a_{k j}\right)^{1 / n}}\right]
$$

subject to:

$$
\begin{gathered}
a_{k j} \in\left[l_{k j}, u_{k j}\right] \forall j>k \\
a_{j k}=1 / a_{k j} \forall j<k \\
a_{j j}=1
\end{gathered}
$$

where $w_{l, i}$ and $w_{u, i}$ are the lower and upper bound of the weight of the $i^{\text {th }}$ element, respectively.

\subsubsection{Group $N-A H P$}

According to Dong, Zhang, Hong and Xu (2010), the most widely used methods for estimating priorities in group AHP decision making processes consist of either the aggregation of individual judgements prior the calculation of the weights, or the aggregation of individual priorities. Given the difficulties in obtaining a consistent aggregated comparison matrix from the first method, the aggregation of individual weights is preferred.

For the aggregation, the relevance of each expert involved must be somehow determined. Biswas, Pramanik and Giri (2016) propose to characterise each DM with a neutrosophic triad $\bar{E}_{k}=\left\langle\delta_{k}, \theta_{k}, \varepsilon_{k}\right\rangle$, being $\bar{E}_{k}$ the triad associated with the $k^{\text {th }}$ expert. Then, the crisp relevance $\varphi_{k}$ of the $k^{\text {th }}$ expert is obtained as the normalised Euclidean distance between the point $\bar{E}_{k}$ and the ideal neutrosophic reliability point $\langle 1,0,0\rangle$ :

$$
\varphi_{k}=\frac{1-\sqrt{\left\{\left(1-\delta_{k}\right)^{2}+{\theta_{k}}^{2}+\varepsilon_{k}^{2}\right\} / 3}}{\sum_{k=1}^{p}\left(1-\sqrt{\left\{\left(1-\delta_{k}\right)^{2}+{\theta_{k}}^{2}+\varepsilon_{k}^{2}\right\} / 3}\right)}
$$


where $\mathrm{p}$ is the number of experts involved in the decision making problem. The mentioned ideal neutrosophic reliability point stands for an element that is true $(T=1)$, absolutely certain $(I=0)$ and not false $(F=0)$ (Dezert, 2002). Sodenkamp, Tavana, \& Di Caprio (2018) suggest an explicit way to define the neutrosophic triad introduced by Biswas et al. (2016). According to Sodenkamp et al. (2018), $\delta_{k}$ shall represent the expert's credibility, $\theta_{k}$ the expert's lack of confidence in his/her statements, and $\varepsilon_{k}$ shall represent a measure of the inconsistencies of the expert's judgements. On the basis of the procedure suggested by Sodenkamp et al. (2018), we propose following expressions for determining the relevance of a DM. First, the expert's credibility is based on his/her experience in the fields being assessed (Sierra, Pellicer, \& Yepes, 2016):

$$
\delta_{k}=\left(\frac{N_{k}}{\max _{k=1 \ldots p}\left\{N_{k}\right\}}+\sum_{i=1}^{4} K c_{i}\right) / 5
$$

where $N_{k}$ are the years of professional experience of the $k^{\text {th }}$ expert, $p$ is the number of experts involved in the decision making problem, and $K c_{i}$ are coefficients defined between 0 and 1 to represent the specific knowledge in the particular fields under consideration. Four coefficients are assumed here to represent the knowledge of the DM in the environmental, economic, social, and design assessment of structures, respectively.

The expert's indeterminacy assessing sustainability is calculated as the mean of the complementary values of the certainties $S C_{i j}$ expressed by the DM for each judgement:

$$
\theta_{k}=\sum_{i, j=1}^{n}\left(1-S C_{i j}\right) /\left(n^{2}\right)
$$

where $\mathrm{n}$ is the number of elements to be compared. At last, the expert's incoherency is determined as the consistency of his/her judgements, measured by means of the consistency ratio (CR) of his/her comparison matrix, divided by the minimum consistency allowed in AHP comparison matrices for the number of elements considered: 


$$
\varepsilon_{k}=C R_{k} / C R_{\text {lim }}
$$

Once the relevance $\varphi_{k}$ of each expert has been defined, the neutrosophic weights of each element shall be aggregated as follows:

$$
\begin{gathered}
W_{m, i}=\sum_{k=1}^{p} \varphi_{k} \cdot w_{m, i}^{k} \\
W_{l, i}=W_{m, i}-\max _{k=1 \ldots p}\left\{w_{m, i}^{k}-w_{l, i}^{k}\right\} \\
W_{u, i}=W_{m, i}+\max _{k=1 \ldots p}\left\{w_{u, i}^{k}-w_{m, i}^{k}\right\}
\end{gathered}
$$

where $W_{m, i}, W_{l, i}$ and $W_{u, i}$ are the center value, the lower and the upper bound, respectively, of the group aggregated neutrosophic weight of element $i$. It shall be noted that the resulting neutrosophic weights obtained hereby are not triangular, but their truth, falsity and indeterminacy functions $\left(\mu_{i}(x), v_{i}(x)\right.$ and $\lambda_{i}(x)$, respectively) follow a generalized membership function defined by the aggregation of the individual membership functions of each expert's weight $w_{i, k}$ centered at $W_{m, i}$. The resulting generalized neutrosophic weights are represented as $\bar{W}_{i}=\left\langle\left(W_{l, i}, W_{m, i}, W_{u, i}\right) ; t_{i}, i_{i}, f_{i}\right\rangle$, with $t_{i}=\sum \varphi_{k} \cdot t_{i k} ; i_{i}=\sum \varphi_{k} \cdot i_{i k}$ and $f_{i}=\sum \varphi_{k} \cdot f_{i k}$ being the maxima of the group aggregated weight membership functions defined within the range $x \in\left[W_{l, i} ; W_{u, i}\right]$.

\subsubsection{Deneutrosophication technique}

The resulting generalized neutrosophic weights shall be transformed into crisp weights using the deneutrosophication technique defined by Sodenkamp et al. (2018) for singlevalued neutrosophic numbers. In this study, the methodology suggested by Sodenkamp et al. (2018) has been extended to handle with multi-valued neutrosophic numbers associated with general defined membership degree functions. This method consists of two steps. Firstly, the neutrosophic weights $\bar{W}_{i}=\left\langle\left(W_{l, i}, W_{m, i}, W_{u, i}\right) ; t_{i}, i_{i}, f_{i}\right\rangle$ are transformed into generalized fuzzy weights $\hat{W}_{i}=\left\langle\left(W_{l, i}, W_{m, i}, W_{u, i}\right) ; \eta_{i}\right\rangle$. The fuzziness function $\eta_{i}(x)$ of weight $\hat{W}_{i}$ is obtained from the Euclidean distance between each point $\left\langle\mu_{i}(x), v_{i}(x), \lambda_{i}(x)\right\rangle$ 
and the ideal neutrosophic estimates reliability point $\langle 1,0,0\rangle$ :

$$
\eta_{i}(x)=1-\sqrt{\left\{\left(1-\mu_{i}(\mathrm{x})\right)^{2}+v_{i}(\mathrm{x})^{2}+\lambda_{i}(\mathrm{x})^{2}\right\} / 3} \quad \forall \mathrm{x} \in\left[\mathrm{W}_{\mathrm{l}, \mathrm{i}} ; \mathrm{W}_{\mathrm{u}, \mathrm{i}}\right]
$$

The second step consists in the defuzzification of the obtained fuzzy weights. The most commonly applied defuzzification technique is the one based on the center of gravity $(\mathrm{CoG})$ of the fuzzy membership function $\eta_{\mathrm{i}}(\mathrm{x})$ :

$$
\operatorname{CoG}_{x}\left(\widehat{W}_{i}\right)=\frac{\int_{x \in\left[W_{l, i}, W_{u, i}\right]} x \cdot \eta_{i}(x) d x}{\int_{x \in\left[W_{l, i}, W_{u, i}\right]} \eta_{i}(x) d x}
$$

However, such one-dimensional technique is only accurate if the maximum of the fuzzy membership function is equal to unity. When handling with general fuzzy numbers, which are not required to fulfill such condition, a two-dimensional approach is preferable. Chu and Tao (2002) improved this technique for its use on generalized fuzzy numbers by proposing a defuzzification based on the area between the centroid point $(x, y)$ of a fuzzy number and the origin of the considered coordinate system. So, an area index is defined as:

$$
S_{\widehat{W}_{i}}=\operatorname{CoG}_{x}\left(\widehat{W}_{i}\right) \cdot \operatorname{CoG}_{y}\left(\widehat{W}_{i}\right)
$$

The synthetical crisp weights of each element $i$ can then be obtained by normalising the resulting area indices for each element under consideration:

$$
W_{i}^{*}=S_{\widehat{W}_{i}} / \sum S_{\widehat{W}_{i}}
$$

\section{Sustainability assessment of bridge preventive designs}

The present paper is intended to analyse the sustainability of different design options for concrete bridges located in coastal environments from a life cycle perspective. The study considers a particular bridge, namely the bridge of Terrón in Galicia (Spain), as the baseline for the definition of the alternative designs. The bridge is $234 \mathrm{~m}$ long and has a span distribution of $5 \times 34.5 \mathrm{~m}+3 \times 50 \mathrm{~m}+34.5 \mathrm{~m}$. It has a continuous box-girder deck which 
is $12.0 \mathrm{~m}$ wide and $2.50 \mathrm{~m}$ deep (www.copasagroup.com). This baseline design is assumed to have a concrete cover of $40 \mathrm{~mm}$, with a passive reinforcement amount of $100 \mathrm{~kg} / \mathrm{m}^{3}$ of concrete, as usual for this type of structures (Fomento, 2000). Regarding the reference concrete mix, a cement content of $350 \mathrm{~kg} / \mathrm{m}^{3}$ is assumed here, with a water/cement ratio of 0.40 (Fomento, 2008).

The most relevant deterioration mechanism of concrete structures exposed to marine environments is derived from the reinforcement corrosion by chlorides. Thus, on the basis of this baseline design (REF hereafter), different alternatives are proposed so as to increase the durability of the reference design against chlorides. First, two alternative designs are considered that increase the concrete cover to $45 \mathrm{~mm}$ and $50 \mathrm{~mm}$ (alternatives CC45 and CC50, respectively). To reduce the chloride diffusivity throughout the cover, the water/cement ratio has been reduced from 0.40 to 0.35 (alternative $\mathrm{C} / \mathrm{W} 35$ ). An alternative way to increase the resistance of concrete against chloride diffusion is the use of additions. Here, additions of $5 \%$ and $10 \%$ silica fume (designs SF5 and SF10, respectively), and additions of $10 \%$ and $20 \%$ fly ash (alternatives FA10 and FA20, respectively) to the baseline concrete are analysed. The addition of polymers, such as styrene butadiene, has shown to be beneficial for the durability performance of concrete in aggressive environments (Yang, Shi, Creighton, \& Peterson, 2009). Consequently, additions of $10 \%$ and $20 \%$ of styrene butadiene latex (alternatives PMC10 and PMC20, respectively) to the original concrete mix have also been considered here. At last, the effect of organic corrosion inhibiting additives to the baseline concrete mix has been studied here as well (alternative OCI hereafter).

The durability of concrete structures exposed to chlorides can also be improved by substituting the conventional carbon steel reinforcement with corrosion resistant steels, such as galvanized or stainless steels. Designs based on both types of steel are 
evaluated here (alternatives GALV and INOX hereafter). To impede the chloride ingress into concrete, surface treatments are often used so as to ensure its isolation from aggressive agents. The present assessment considers hydrophobic and sealant surface treatments, applied periodically to the reference design (alternatives HYDRO and SEAL, respectively). The last type of design option considered in this study consists in the use of cathodic protection of the reinforcing steel bars by impressed current (alternative ICCP).

In total, 16 different options are presented here as alternative design options to the baseline bridge design. Table 2 shows the concrete mixes resulting for each design. The sustainability performance of each alternative will depend, among other aspects, on their respective maintenance needs (García-Segura et al., 2018). The following sub-sections describe how maintenance needs are calculated, as well as how the different life cycle impacts are quantified.

\begin{tabular}{|c|c|c|c|c|c|c|c|c|c|}
\hline Concrete mix components & $\mathrm{REF}^{1}$ & $\mathrm{~W} / \mathrm{C} 35$ & SF5 & SF10 & FA10 & FA20 & PMC10 & PMC20 & $\overline{\mathrm{OCI}}$ \\
\hline Cement $\left(\mathrm{kg} / \mathrm{m}^{3}\right)$ & 350.0 & 350.0 & 315.0 & 280.0 & 339.5 & 329.0 & 350.0 & 350.0 & 350.0 \\
\hline Water $\left(1 / \mathrm{m}^{3}\right)$ & 140.0 & 122.5 & 140.0 & 140.0 & 140.0 & 140.0 & 140.0 & 140.0 & 140.0 \\
\hline Gravel $\left(\mathrm{kg} / \mathrm{m}^{3}\right)$ & 1016.9 & 1037.0 & 1016.9 & 1016.9 & 1016.9 & 1016.9 & 1016.9 & 1016.9 & 1016.9 \\
\hline Sand $\left(\mathrm{kg} / \mathrm{m}^{3}\right)$ & 1067.8 & 1094.9 & 1098.2 & 1128.7 & 1076.9 & 1086.1 & 1067.8 & 1067.8 & 1067.8 \\
\hline Fly Ash $\left(\mathrm{kg} / \mathrm{m}^{3}\right)$ & & & & & 35.0 & 70.0 & & & \\
\hline Silica Fume $\left(\mathrm{kg} / \mathrm{m}^{3}\right)$ & & & 17.5 & 35.0 & & & & & \\
\hline \multicolumn{10}{|l|}{ Styrene Butadiene Latex } \\
\hline$\left(\mathrm{kg} / \mathrm{m}^{3}\right)$ & & & & & & & 35.0 & 70.0 & \\
\hline Organic Inhibitor $\left(\mathrm{kg} / \mathrm{m}^{3}\right)$ & & & & & & & & & 10.5 \\
\hline Plasticiser $\left(\mathrm{kg} / \mathrm{m}^{3}\right)$ & 5.25 & 7.00 & 4.73 & 4.20 & 5.09 & 4.94 & & & \\
\hline $\mathrm{f}_{\mathrm{ck}}(\mathrm{MPa})$ & 46.5 & 54.8 & 46.5 & 46.5 & 46.5 & 46.5 & 58.1 & 58.1 & 58.1 \\
\hline $\mathrm{E}_{\mathrm{c}}(\mathrm{GPa})$ & 31 & 32 & 31 & 31 & 31 & 31 & 33 & 33 & 33 \\
\hline
\end{tabular}

Table 2. Concrete mixes assumed in each design option 


\subsection{Reliability-based maintenance}

Reinforcement corrosion in concrete occurs when the concentration of chlorides at the rebars is high enough to trigger this aggressive phenomenon. Such concentration is called the critical chloride content $\left(C_{c r}\right)$, and depends mainly on the properties of the reinforcing steel. However, a certain time is needed for the chlorides to penetrate the concrete cover and reach this threshold at the bars. The advance of the chloride front follows a diffusive process that depends on the resistance that the concrete cover opposes to it. To evaluate the time-dependent evolution of the chloride concentration in concrete, a two-dimensional version of the Fickean model proposed in Fib Bulletin 34 (Fib, 2006) is used. Thus, the chloride concentration $C(x, y, t)$ at any depth in both $x$ and $y$ directions and at any time $t$ is given by:

$$
C(x, y, t)=C_{s} \cdot\left\{1-\operatorname{erf}\left(\frac{x}{2 \sqrt{D_{0} \cdot\left(\frac{t_{0}}{t}\right)^{\alpha} \cdot t}}\right) \cdot \operatorname{erf}\left(\frac{y}{2 \sqrt{D_{0} \cdot\left(\frac{t_{0}}{t}\right)^{\alpha} \cdot t}}\right)\right\}
$$

where $x$ and $y$ are measured from the exposed concrete surfaces (in $\mathrm{mm}$ ), $t$ is the time of evaluation (in years), $C_{s}$ is the surface chloride concentration (in wt\%/binder), $D_{0}$ is the chloride diffusivity of the concrete cover $\left(\mathrm{mm}^{2} /\right.$ year), assumed to be homogeneous in space, and $\operatorname{erf}(\cdot)$ is the Gaussian error function. Given the closeness of the concrete deck under analysis to the sea water level, a surface chloride concentration $C_{s}=3.29 \%$ is assumed here (Fomento, 2008). In the present analysis, the reference time $t_{0}$ is considered to be $t_{0}=0.0767$ years ( 28 days), and the age factor $\alpha$ is assumed to be 0.5 (Fomento, 2008). The particular values for the durability parameters considered here for each design alternative are based on Navarro, Martí, \& Yepes (2019) and are presented in Table 3.

\begin{tabular}{ccccccc}
\hline Design & \multicolumn{2}{c}{$\mathrm{D}_{0}\left(\mathrm{x}^{-12} \mathrm{~m}^{2} / \mathrm{s}\right)$} & \multicolumn{2}{c}{$\mathrm{C}_{\mathrm{cr}}(\%)$} & \multicolumn{2}{c}{ Cover $(\mathrm{mm})$} \\
Option & Mean & Std.Dev. & Mean & Std.Dev. & Mean & Std.Dev. \\
& & & & & & \\
\hline REF & 8.90 & 0.90 & 0.60 & 0.10 & 40 & 2
\end{tabular}




\begin{tabular}{ccccccc} 
CC45 & 8.90 & 0.90 & 0.60 & 0.10 & 45 & 2.25 \\
CC50 & 8.90 & 0.90 & 0.60 & 0.10 & 50 & 2.5 \\
W/C35 & 5.80 & 0.47 & 0.60 & 0.10 & 40 & 2 \\
INOX & 8.90 & 0.90 & 5.00 & 0.94 & 40 & 2 \\
GALV & 8.90 & 0.90 & 1.20 & 0.21 & 40 & 2 \\
SF5 & 2.94 & 0.23 & 0.60 & 0.06 & 40 & 2 \\
SF10 & 1.23 & 0.17 & 0.60 & 0.03 & 40 & 2 \\
FA10 & 5.48 & 0.43 & 0.60 & 0.10 & 40 & 2 \\
FA20 & 4.65 & 0.35 & 0.60 & 0.10 & 40 & 2 \\
PMC10 & 6.51 & 0.55 & 0.60 & 0.10 & 40 & 2 \\
PMC20 & 2.71 & 0.22 & 0.60 & 0.10 & 40 & 2 \\
HYDRO & 6.88 & 0.60 & 0.60 & 0.10 & 40 & 2 \\
SEAL & 4.33 & 0.33 & 0.60 & 0.10 & 40 & 2 \\
OCI & 3.55 & 0.27 & 0.60 & 0.10 & 40 & 2 \\
ICCP & 8.90 & 0.90 & 0.60 & 0.10 & 40 & 2 \\
\hline & & & & & 2 \\
\hline
\end{tabular}

In the present assessment, maintenance operations are envisaged at most when the critical chloride threshold is reached at the outermost reinforcement. At this point, the rebars are still not corroded, and maintenance will basically consist of the replacement of the contaminated cover. However, if preventive maintenance is undertaken, i.e. before $C_{c r}$ is reached at the rebars, only the affected cover depth is substituted. It shall be noted that the nature of some of the alternatives considered here imposes certain limits on the maximum allowed maintenance interval. So, in the design based on impressed current (ICCP), the titanium anode mesh must be replaced at most every 20 years according to manufacturer's specifications. Consequently, if the durability of ICCP results to be greater than 20 years, maintenance will consist only in the demolition of the $15 \mathrm{~mm}$ anode cover, the replacement of the titanium mesh, and the regeneration of the concrete cover. In the case of hydrophobic and sealant surface treatments, manufacturers usually require them to be re-applied every 5 years to ensure an adequate isolation level. In that case, the maintenance of the HYDRO and SEAL alternatives will simply consist of the new application of these treatments without the need to replace the cover. 
The present assessment intends not only to find the most sustainable design, but its optimal maintenance interval as well. So, the life cycle impacts are quantified for each design considering every possible maintenance interval $t$ for which a target failure probability (expressed in terms of a target reliability $\beta_{\text {lim }}$ ) is not exceeded:

$$
\beta(t)=-\Phi^{-1}\left[p_{f}(t)\right] \geq \beta_{\text {lim }}
$$

where $\Phi^{-1}(\cdot)$ represents the inverse Gaussian cumulative distribution function. The annual reliability $\beta(\mathrm{t})$ of a particular design represents its probability of failure $p_{f}$ at the time of evaluation $t$, and is evaluated by means of Monte Carlo simulations. In particular, 30000 simulations have been needed here so as to get convergent results. Table 3 shows the stochastic characterization of the durability parameters assumed in this analysis. In this study, a durability limit state is assumed based on the deterioration mechanism induced by chlorides exposed above. Here, the structure is considered to reach an unacceptable state when the chloride content at the steel rebars exceeds the critical chloride threshold, i.e. $C(x, y, t)>C_{c r}$. Consequently, the limit state function $g$ assumed for the evaluation of the reliability index shall be formulated as:

$$
g=R-S=C_{c r}-C(x, y, t)
$$

where $R$ represents the resistance of the structure against the considered deterioration mechanism, and $S$ represents the deteriorating action. In this case, the deterioration advance is represented by the chloride concentration in the concrete cover at any time $t$, namely $S=C(x, y, t)$. The resistance of the structure against chloride corrosion of the steel is $R=C_{c r}$. Considering that this failure mode does not compromise the structural integrity of the deck, the limit state assumed here shall be considered as a serviceability limit state. Consequently, a target reliability index $\beta_{\text {lim }}=1.30$ is assumed here (Nogueira, Leonel, \& Coda, 2012). Given the medium-high relative economic costs 
associated to bridge deck cover replacement, and given the small consequences of the proposed failure, such target reliability index is in good accordance with the recommendations of standards and codes such as ISO (2015) and JCSS (2001). In this study, it is assumed that each maintenance operation restores the reliability of the deck to its initial state (Stewart, Estes, \& Frangopol, 2004). But for the designs based on surface treatments or impressed current, such assumption implies a complete restoration of the contaminated concrete cover depth of the chloride exposed deck surface. By doing so, the appearance of cracks derived from shrinkage-related deformation incompatibilities between a locally applied repair concrete and the existing one is avoided.

\subsection{Life cycle assessment}

The main goal of the present study is first to analyse the life cycle impacts of alternative bridge designs from an economic, environmental and social perspective, and then to apply an MCDM model to evaluate and compare the resulting sustainability of each of these designs. According to ISO 14040 (ISO, 2006), a rigorous life cycle assessment requires an adequate functional unit to be defined, and the system boundaries, the impact assessment techniques and the impact inventories to be clearly presented. Following sub-sections are intended for that purpose.

\subsubsection{Functional unit}

Both the economic, the environmental and the social life cycle assessments (LCCA, LCA and SLCA, respectively) must be based on the same functional unit in order to compare the results. The functional unit considered in this analysis is a $1 \mathrm{~m}$ long section of a $12 \mathrm{~m}$ wide concrete bridge deck providing vehicular and pedestrian connection between Vilanova de Arousa and the Southern sector of the village on the other side of the existing estuary, including the construction and maintenance works required to guarantee a service 
life of the structure of 100 years. The baseline design is assumed to provide the described functionality.

The alternative designs shall not only result in the same service life as the reference option, but shall present the same structural behavior as well. As some of the alternatives have greater stiffness values than that of the baseline design, the deck depth in those cases has been modified so that the resulting structural behavior under ultimate and serviceability limit states matches the response of the reference design (Navarro et al., 2019). Consequently, the design W/C35 has resulted in a structural deck depth of $2.437 \mathrm{~m}$, and the options PMC10 and PMC20 in a depth of $2.416 \mathrm{~m}$.

\subsubsection{System boundaries}

The system under analysis covers from the production of the different construction materials in their respective production centres up to the end of the service life of the bridge, where the structure is supposed to be demolished. So, a "gate-to-grave" approach has been followed, considering the impacts derived from the materials production involved both in the construction phase and during the maintenance phase, from the transport activities held, as well as from the specific construction and maintenance activities undertaken at the structure location. As a cut-off criterion, and considering the comparison-oriented scope of the present assessment, processes identical and common to every alternative have been excluded from the system definition (Martínez-Blanco et al., 2014). Consequently, the activities related to the execution and maintenance of the road pavement, the bridge piers, the tendons prestressing or the wall parapets of the deck have been excluded. Figure 2 summarises the system boundaries considered in this assessment. 


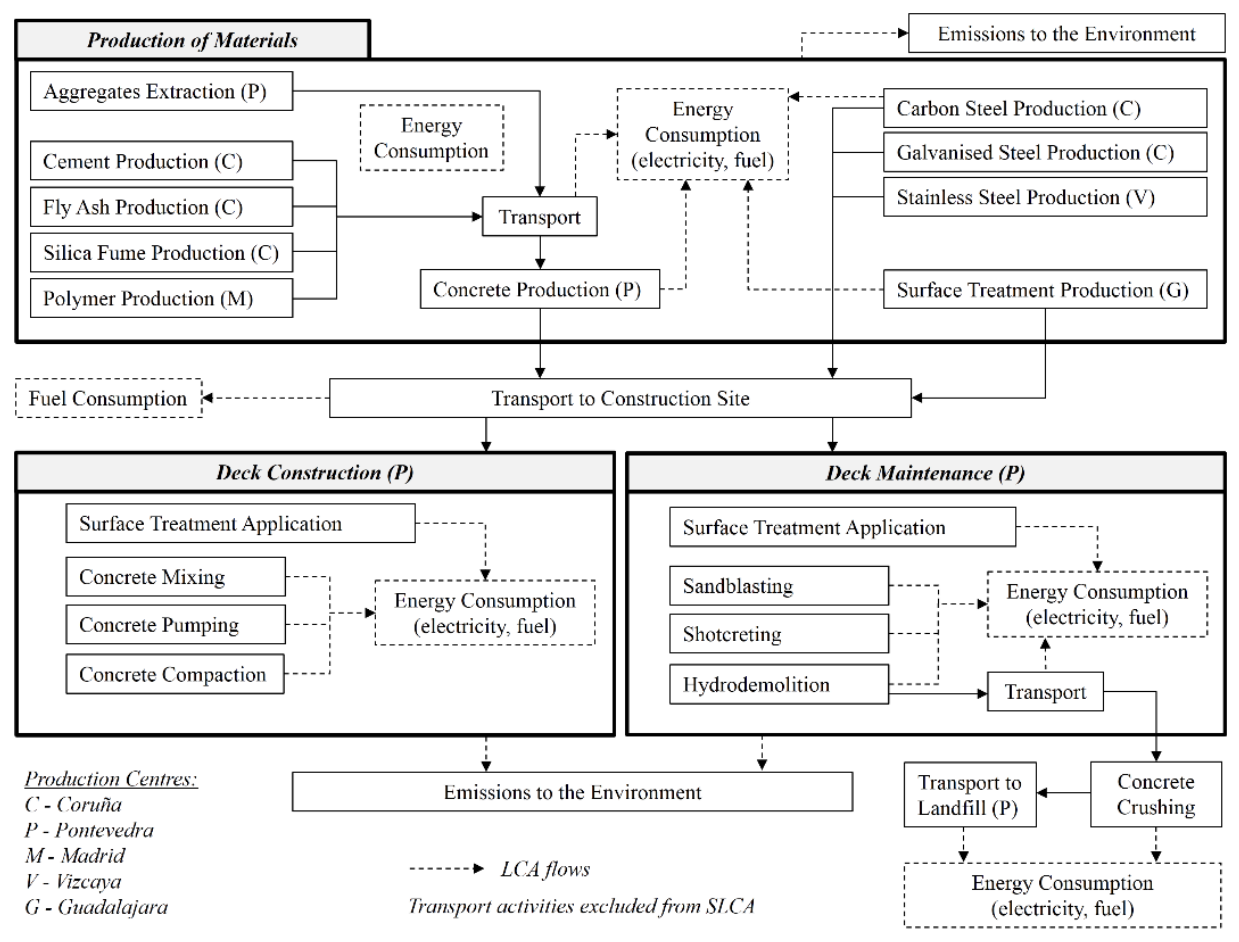

Figure 2. System boundaries considered in the sustainability assessment

\subsubsection{Impact assessment}

The assessment of the environmental life cycle impacts follows the ReCiPe 2008 methodology (Goedkoop et al., 2009). This method allows for the conversion of 18 midpoint indicators into 3 endpoint indicators, namely damage to human health, depletion of natural resources, and damage to ecosystems. Further information on the environmental assessment can be found in Navarro et al. (2019).

Regarding the economic impacts, no assessment phase exists as such, as all the impacts are expressed in the same unit of measure and no normalization of the inventory data is required (Swarr et al., 2011). Here, two different economic impact categories are identified, namely the costs associated with the construction of the structure, and the discounted costs derived from the different maintenance needs in which the design incurs throughout its service life. There is no consensus on which discount rate is more appropriate to choose when assessing the life cycle costs of a particular product, in this case a structure. High discount rates, which are usually preferred from a private 
perspective, emphasize costs in the near future, almost neglecting future expenses. Such approach is not consistent with the definition of sustainability. According to the definition of sustainable development first established in 1987 by the Brundtland Commission, sustainability seeks to ensure the satisfaction of present needs without compromising the capacity of future generations to satisfy their own (WCED, 1987). Consequently, so as to give relevance to future expenses that will burden coming generations, a lower, social discount rate of $2 \%$ (Allacker, 2012) has been chosen for the present sustainabilityoriented assessment.

At last, social impacts are assessed following the indicator-based methodology proposed by Navarro et al. (2018b) for bridge structures. This methodology considers four impact categories to evaluate the effects that the construction and maintenance activities have on different stakeholders. The first impact category includes the workers involved both in the material production and in the installation and maintenance activities. Gender discrimination levels, the unemployment rates and the salaries of the particular regions, as well as the safety level at the particular working places are considered here as sub-categories. The second category comprises the users of the infrastructure, and considers how maintenance affects the accessibility and safety of the users. The third category evaluates the public opinion of the local community towards infrastructure. In particular, it takes into consideration how maintenance works alter the aesthetics of the construction site, as well as the impacts derived from the noise or vibration problems resulting from such works. Finally, this assessment method considers the effects that the alternative designs have on the economic development of the regions included in the product system of each option. This methodology considers as activity variables the working time and the economic flows in each region within the system boundaries (UNEP/SETAC, 2009). It shall be noted that the impact categories to be considered in a 
SLCA depend on the social context of the structure under evaluation. Given the geographical proximity of the structure to be assessed here and the bridge analysed by Navarro et al. (2018b), the same social impact categories have been assumed.

In summary, 9 different impact categories are considered for the present sustainability assessment: damage to human health, damage to the ecosystems and the natural resources depletion, the construction and maintenance costs, and the social impacts on workers, on infrastructure users, on local communities and on the economic development of the regions. Impact categories are considered as decision criteria in the present MCDM assessment. Table 4 summarises the decision criteria assumed here. A sustainability indicator is then obtained by applying TOPSIS MCDM technique taking into consideration the criteria weights resulting after applying the exposed neutrosophic group AHP technique.

\begin{tabular}{lcl}
\hline Sustainability Field & Criterion Id. & Criterion description \\
\hline Economy & 1 & Construction Costs \\
& 2 & Maintenance and EOL Costs \\
Environment & 3 & Damage to Human Health \\
& 4 & Damage to Ecosystem \\
& 5 & Damage to Resource Availability \\
Society & 6 & Workers \\
& 7 & Economic development \\
8 & Consumer \\
9 & Local Community \\
\hline
\end{tabular}

Table 4. Criteria considered in the present sustainability MCDM assessment

\subsubsection{Inventory analysis}

The inventory data relevant for the environmental characterization of the different activities to be assessed have been gathered from the database Ecoinvent 3.2. This information has been complemented with the performance values and energy consumption rates of the different production activities presented in Table 5. 


\begin{tabular}{lcc}
\hline \multicolumn{1}{c}{ Activity } & Performance & Energy Demand/Machine Power \\
\hline Concrete mixing & $7.2 \mathrm{~min} / \mathrm{m}^{3}$ & $75 \mathrm{~kW}$ \\
Galvanization $^{1}$ & $0.3 \mathrm{kWh} / \mathrm{kg}$ \\
Emulsion mixing $^{1}$ & $120 \mathrm{l} / \mathrm{h}$ & $0.025 \mathrm{kWh} / \mathrm{kg}$ \\
Hydrophobic surface treating & $1.3 \mathrm{~kW}$ \\
Cathodic protection ${ }^{1}$ & $0.6 \mathrm{~m}^{3} / \mathrm{h}$ & $0.75 \mathrm{~kW}$ \\
Cover hidrodemolition & $13.2 \mathrm{~m}^{2} / \mathrm{h}$ & $2.271 \mathrm{fuel} / \mathrm{h}$ \\
Reinforcement sandblasting & $18 \mathrm{~m}^{3} / \mathrm{h}$ & $26.5 \mathrm{~kW}$ \\
Shotcreting & & \\
\hline 1. Where activity performance is not given, energy demand is provided $\mathrm{per}$ unit of product
\end{tabular}

Table 5. Life cycle inventory data regarding activity processes

The transport distances existing between the assumed material production sites and the structure location are shown in Table 6. The assessment of the transport impacts is based on the premise that when the transport distance exceeds $100 \mathrm{~km}, 80 \%$ of the route is done by freight train. The environmental impacts associated to industry by-products, such as fly ash or silica fume, have been allocated economically according to Chen, Habert, Boudizi, Jullien, \& Ventura (2010). For the environmental assessment, it has been assumed that the demolished concrete resulting from both the maintenance activities as well as from the demolition of the structure itself is recycled to serve as embankment protection. The present analysis accounts for the environmental effect of the atmospheric $\mathrm{CO}_{2}$ uptake resulting from the carbonation of this concrete. More detailed information on the environmental inventory data can be found in the studies by Navarro et al. (2018c, 2019).

\begin{tabular}{lc}
\hline \multicolumn{1}{c}{ Production process } & Transport distance $(\mathrm{km})$ \\
\hline Aggregates & $14^{1}$ \\
Portland cement & $12^{1}$ \\
Fly ash & $101^{1}$ \\
Silica fume & $93.1^{1}$ \\
Styrene butadiene latex, Plasticiser & $649^{1}$ \\
Organic inhibitor & $632^{1}$
\end{tabular}




\begin{tabular}{lc} 
Concrete & $13.3^{2}$ \\
Carbon and Galvanised steel & $147^{2}$ \\
Stainless steel & $640^{2}$ \\
Hydrophobic and sealant treatments & $708^{2}$ \\
Cathodic protection & $650^{2}$ \\
Landfill & 20 \\
\hline 1. Distance to concrete production facility & \\
2. Distance to installation site &
\end{tabular}

Table 6. Inventory data regarding transport activities

As regards the economic inventory, data on the costs concerning construction materials and activities have been obtained from national construction specific databases. The unitary costs considered for each foreground concept are presented in Table 7 . These costs are updated in 2019 and include the indirect costs of each background process along each product's life cycle (Martínez-Blanco et al., 2014), such as those associated with raw materials extraction, energy consumption or transportation activities.

\begin{tabular}{|c|c|c|c|c|c|c|c|c|}
\hline \multirow{4}{*}{ Product } & Steel & Cement & Concrete & Additives & Surf. treat. & Cathodic & Installation & \\
\hline & Prod. & Prod. & Prod. & Prod. & Prod. & System & \multirow{3}{*}{\multicolumn{2}{|c|}{ (Pontevedra) }} \\
\hline & & & & & & Prod. & & \\
\hline & (Coruña) & (Coruña) & (Pontevedra) & (Madrid) & (Guadalajara) & (Madrid) & & \\
\hline HA-30 (REF) & & 30.72 & 31.69 & & & & 31.56 & $€ / \mathrm{m}^{3}$ \\
\hline HA-30 (W/C35) & & 30.72 & 32.38 & & & & 36.68 & $€ / \mathrm{m}^{3}$ \\
\hline HA-30 (FA10) & & 44.75 & 33.15 & & & & 31.34 & $€ / \mathrm{m}^{3}$ \\
\hline HA-30 (FA20) & & 43.37 & 34.61 & & & & 31.12 & $€ / \mathrm{m}^{3}$ \\
\hline HA-30 (SF5) & & 41.52 & 52.07 & & & & 42.43 & $€ / \mathrm{m}^{3}$ \\
\hline HA-30 (SF10) & & 36.91 & 72.44 & & & & 30.11 & $€ / \mathrm{m}^{3}$ \\
\hline HA-30 (HMP10) & & 46.14 & 31.69 & 173.55 & & & 24.33 & $€ / \mathrm{m}^{3}$ \\
\hline HA-30 (HMP20) & & 46.14 & 31.69 & 347.10 & & & 24.33 & $€ / \mathrm{m}^{3}$ \\
\hline HA-30 (OCI) & & 30.72 & 31.69 & 70.60 & & & 31.56 & $€ / \mathrm{m}^{3}$ \\
\hline Carbon steel & 0.86 & & & & & & 0.38 & $€ / \mathrm{kg}$ \\
\hline Stainless steel & 4.86 & & & & & & 0.38 & $€ / \mathrm{kg}$ \\
\hline Galvanised steel & 3.24 & & & & & & 0.38 & $€ / \mathrm{kg}$ \\
\hline Hydrophobic & & & & & 2.87 & & 1.62 & $€ / \mathrm{m}^{2}$ \\
\hline treatment & & & & & & & & \\
\hline Sealant & & & & & 14.13 & & 1.62 & $€ / \mathrm{m}^{2}$ \\
\hline
\end{tabular}




\begin{tabular}{|c|c|c|c|}
\hline Impressed & 37.10 & 26.44 & $€ / \mathrm{m}^{2}$ \\
\hline \multicolumn{4}{|l|}{ current system } \\
\hline $40 \mathrm{~mm}$ cover & & 27.68 & $€ / \mathrm{m}^{2}$ \\
\hline \multicolumn{4}{|l|}{ Hydrodemolition } \\
\hline Sandblasting and & & 16.02 & $€ / \mathrm{m}^{2}$ \\
\hline \multicolumn{4}{|l|}{ reinforcement } \\
\hline priming & & & \\
\hline
\end{tabular}

Table 7. Economic flows per output unit

To properly characterise the social context of each activity location, data have been gathered from national statistical databases, in particular from the Spanish Tax Office and the Spanish National Statistics Institute. Given the long-term perspective of the present assessment, the expected values for each social parameter have been obtained from the analysis of the historical series of the gathered data. Table 8 presents the expected values of each social parameter in terms of most probable, maximum and minimum.

\begin{tabular}{|c|c|c|c|c|c|}
\hline $\begin{array}{l}\text { Social } \\
\text { background data }\end{array}$ & Pontevedra & A Coruña & Vizcaya & Madrid & Guadalajara \\
\hline $\begin{array}{l}\text { Unemployment } \\
\text { rate }(\%)\end{array}$ & $(7.5-16.8-25.8)$ & $(6.8-13.9-21.7)$ & $\begin{array}{c}(6.6-12.5- \\
18.9)\end{array}$ & $(5.9-12.4-20.5)$ & $\begin{array}{l}(3.3-14- \\
24.9)\end{array}$ \\
\hline $\begin{array}{l}\text { Men } \\
\text { unemployment } \\
(\%)\end{array}$ & $(5.7-15-26.1)$ & $(4.7-12.5-22.8)$ & $\begin{array}{c}(4.9-11.8- \\
19.8)\end{array}$ & $(3.9-11.6-20)$ & $\begin{array}{c}(2.2-12.2- \\
24.2)\end{array}$ \\
\hline $\begin{array}{l}\text { Women } \\
\text { unemployment } \\
(\%)\end{array}$ & $(8.3-19.1-26.4)$ & $(8.5-15.8-22.2)$ & $\begin{array}{c}(7.7-13.4- \\
18.7)\end{array}$ & $(6.8-13.3-21.9)$ & $\begin{array}{c}(3.7-16.7- \\
29.1)\end{array}$ \\
\hline $\begin{array}{l}\text { Salary } \\
\left(\times 10^{3} € / \text { year }\right)\end{array}$ & $\begin{array}{l}(18-19.6-20.6)^{1} \\
(13.1-14.3-14.9)^{2}\end{array}$ & $(18-19.6-20.6)$ & $\begin{array}{c}(19.7-20.3- \\
21.6)\end{array}$ & $(27.9-32-34.6)$ & $\begin{array}{c}(21.4-23.6- \\
25)\end{array}$ \\
\hline $\begin{array}{l}\text { Men salary } \\
\left(\times 10^{3} € / \text { year }\right)\end{array}$ & $(17.8-18.8-19.6)$ & $\begin{array}{c}(19.8-20.9- \\
21.7)\end{array}$ & $\begin{array}{c}(26.6-28.2- \\
29.5)\end{array}$ & $(26.6-27.4-28)$ & $\begin{array}{c}(20.6-21.9- \\
22.7)\end{array}$ \\
\hline $\begin{array}{l}\text { Women salary } \\
\left(\times 10^{3} € / \text { year }\right)\end{array}$ & $(13.6-14.2-14.8)$ & $\begin{array}{c}(15.2-15.9- \\
16.5)\end{array}$ & $\begin{array}{c}(19.3-20.1- \\
21.1)\end{array}$ & $\begin{array}{c}(19.3-20.1- \\
20.8)\end{array}$ & $\begin{array}{c}(15.7-16- \\
16.3)\end{array}$ \\
\hline
\end{tabular}




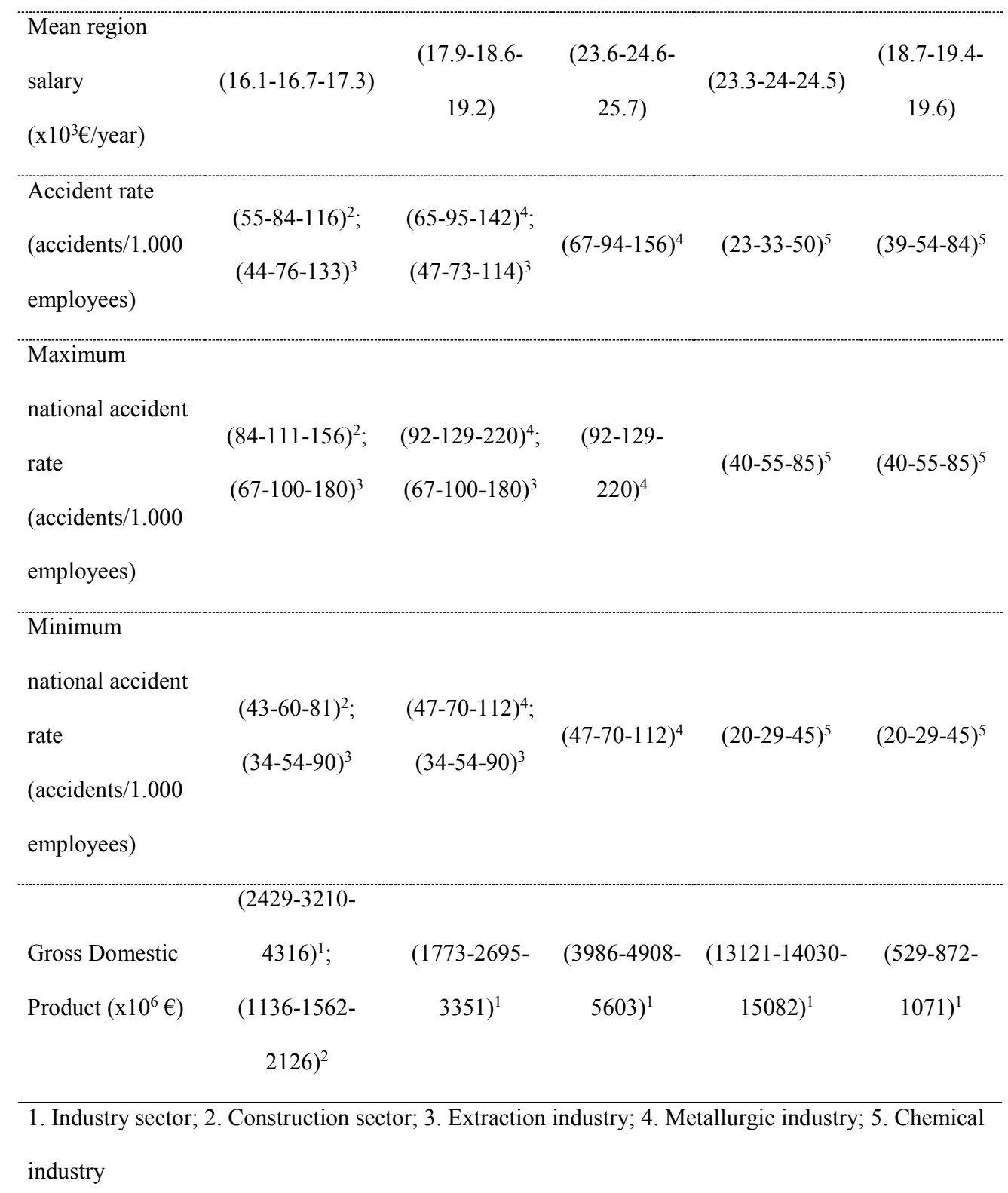

Table 8. Expected social inventory data of each production location, based on Navarro et al. (2018b)

From these values, a Beta-PERT distribution is assigned to each social indicator to quantify its expected variability over time (Navarro et al., 2018b). To evaluate the working time related to material production and construction/maintenance activities, data have been gathered from both local companies and official construction databases provided by Spanish regional governments. The considered performance values are shown in Table 9. To evaluate the regional economic development, the regional economic flows presented in Table 7 have been used.

\begin{tabular}{ll}
\hline Activity & Unitary working time \\
\hline
\end{tabular}




\begin{tabular}{ll} 
Cement production & $0.17 \mathrm{~h} / \mathrm{tn}$ \\
Aggregates extraction & $0.19 \mathrm{~h} / \mathrm{tn}$ \\
Concrete production & $0.18 \mathrm{~h} / \mathrm{tn}$ \\
Hydro. treatment production & $0.05 \mathrm{~h} / \mathrm{m}^{2}$ \\
Seal. treatment production & $0.07 \mathrm{~h} / \mathrm{m}^{2}$ \\
Polymer production & $0.03 \mathrm{~h} / 1$ \\
Inhibitor production & $0.04 \mathrm{~h} / \mathrm{kg}$ \\
Carbon steel production & $0.41 \mathrm{~h} / \mathrm{tn}$ \\
Galvanised steel production & $0.41 \mathrm{~h} / \mathrm{tn}$ \\
Stainless steel production & $4.90 \mathrm{~h} / \mathrm{tn}$ \\
Concreting & $0.35 \mathrm{~h} / \mathrm{m}^{3}$ \\
Steel disposal & $0.02 \mathrm{~h} / \mathrm{kg}$ \\
Concrete surface treatment & $0.11 \mathrm{~h} / \mathrm{m}^{2}$ \\
Steel surface treatment & $0.12 \mathrm{~h} / \mathrm{m}^{2}$ \\
40 mm cover demolition & $0.36 \mathrm{~h} / \mathrm{m}^{2}$ \\
40 mm cover repair & $1.12 \mathrm{~h} / \mathrm{m}^{2}$ \\
\hline Table 9. Working time performance of each activity
\end{tabular}

\section{Results and discussion}

\subsection{Neutrosophic Group AHP results}

The present section shows the results of the neutrosophic group weighting method exposed in Section 2.2.2. In particular, a group of three experts has been consulted. Each of them has been required to make pairwise comparisons regarding the nine decision criteria defined above. Was the resulting comparison matrix not consistent, the DM was required to repeat the process until the resulting matrix consistency ratio fell below 0.10 . The comparison matrices $A_{D M i}$ for each DM are presented below. It shall be noted that each element $\mathrm{a}_{\mathrm{jk}}$ of these matrices represents the judgement emitted by the decision maker $\mathrm{DM}_{\mathrm{i}}$ when comparing the decision criterion $j$ with the criterion $k$. The identification number assigned to each criterion follows the criterion Id presented in Table 4. 
The comparison matrix of the first decision maker $A_{D M 1}$ is shown below. The matrix containing the certainty expressed by the expert on each of his/her judgements $S C_{D M 1}$ is also presented. As with the comparison matrices, each element $s c_{j k}$ of the certainty matrices represent the certainty expressed by the decision maker $\mathrm{DM}_{\mathrm{i}}$ when comparing criterion $j$ and criterion $k$, according to Table 4 .

$$
\begin{aligned}
A_{D M 1} & =\left[\begin{array}{ccccccccc}
1 & 1 / 3 & 1 / 6 & 1 / 6 & 1 / 6 & 1 / 3 & 1 / 4 & 1 / 4 & 1 / 4 \\
3 & 1 & 1 / 2 & 1 / 5 & 1 / 4 & 1 / 2 & 3 & 1 / 2 & 1 / 2 \\
6 & 2 & 1 & 1 & 1 / 2 & 3 & 7 & 6 & 6 \\
6 & 5 & 1 & 1 & 1 / 2 & 3 & 7 & 6 & 6 \\
6 & 4 & 2 & 2 & 1 & 2 & 6 & 5 & 5 \\
3 & 2 & 1 / 3 & 1 / 3 & 1 / 2 & 1 & 2 & 1 / 2 & 1 / 2 \\
4 & 1 / 3 & 1 / 7 & 1 / 7 & 1 / 6 & 1 / 2 & 1 & 1 / 2 & 1 / 2 \\
4 & 2 & 1 / 6 & 1 / 6 & 1 / 5 & 2 & 2 & 1 & 1 \\
4 & 2 & 1 / 6 & 1 / 6 & 1 / 5 & 2 & 2 & 1 & 1
\end{array}\right] \\
S C_{D M 1} & =\left[\begin{array}{cccccccccc}
1 & 0.8 & 0.5 & 0.7 & 0.9 & 0.8 & 0.8 & 0.6 & 0.2 \\
0.8 & 1 & 0.7 & 0.8 & 0.6 & 0.6 & 0.4 & 0.7 & 0.7 \\
0.5 & 0.7 & 1 & 0.8 & 0.8 & 0.7 & 0.8 & 0.7 & 0.6 \\
0.7 & 0.8 & 0.8 & 1 & 0.8 & 0.3 & 0.4 & 0.5 & 0.6 \\
0.9 & 0.6 & 0.8 & 0.8 & 1 & 0.2 & 0.7 & 0.6 & 0.4 \\
0.8 & 0.6 & 0.7 & 0.3 & 0.2 & 1 & 0.8 & 0.8 & 0.4 \\
0.8 & 0.4 & 0.8 & 0.4 & 0.7 & 0.8 & 1 & 0.5 & 0.5 \\
0.6 & 0.7 & 0.7 & 0.5 & 0.6 & 0.8 & 0.5 & 1 & 0.4 \\
0.2 & 0.7 & 0.6 & 0.6 & 0.4 & 0.4 & 0.5 & 0.4 & 1
\end{array}\right]
\end{aligned}
$$

The comparison matrix and certainty matrix of the second expert are presented below:

$$
\begin{aligned}
A_{D M 2} & =\left[\begin{array}{ccccccccc}
1 & 3 & 1 / 3 & 1 / 3 & 1 / 5 & 7 & 7 & 5 & 9 \\
1 / 3 & 1 & 1 / 3 & 1 / 3 & 1 / 5 & 7 & 7 & 1 / 3 & 3 \\
3 & 3 & 1 & 1 & 1 / 2 & 7 & 5 & 5 & 9 \\
3 & 3 & 1 & 1 & 1 / 3 & 7 & 5 & 5 & 9 \\
5 & 5 & 2 & 3 & 1 & 7 & 7 & 5 & 7 \\
1 / 7 & 1 / 7 & 1 / 7 & 1 / 7 & 1 / 7 & 1 & 1 & 1 / 2 & 1 / 2 \\
1 / 7 & 1 / 7 & 1 / 5 & 1 / 5 & 1 / 7 & 1 & 1 & 1 / 2 & 1 / 2 \\
1 / 5 & 3 & 1 / 5 & 1 / 5 & 1 / 5 & 2 & 2 & 1 & 1 \\
1 / 9 & 1 / 3 & 1 / 9 & 1 / 9 & 1 / 7 & 2 & 2 & 1 & 1
\end{array}\right] \\
S C_{D M 2} & =\left[\begin{array}{cccccccccc}
1 & 0.7 & 0.6 & 0.6 & 0.6 & 0.8 & 0.8 & 0.8 & 0.9 \\
0.7 & 1 & 0.5 & 0.5 & 0.6 & 0.8 & 0.9 & 0.4 & 0.8 \\
0.6 & 0.5 & 1 & 0.4 & 0.4 & 0.7 & 0.6 & 0.6 & 0.8 \\
0.6 & 0.5 & 0.4 & 1 & 0.7 & 0.7 & 0.7 & 0.7 & 0.9 \\
0.6 & 0.6 & 0.4 & 0.7 & 1 & 0.8 & 0.8 & 0.7 & 0.8 \\
0.8 & 0.8 & 0.7 & 0.7 & 0.8 & 1 & 0.6 & 0.6 & 0.6 \\
0.8 & 0.9 & 0.6 & 0.7 & 0.8 & 0.6 & 1 & 0.7 & 0.8 \\
0.8 & 0.4 & 0.6 & 0.7 & 0.7 & 0.6 & 0.7 & 1 & 0.8 \\
0.9 & 0.8 & 0.8 & 0.9 & 0.8 & 0.6 & 0.8 & 0.8 & 1
\end{array}\right]
\end{aligned}
$$

At last, the comparison and the certainty matrices of the third DM are presented below: 


$$
\begin{aligned}
& A_{D M 3}=\left[\begin{array}{ccccccccc}
1 & 6 & 1 / 5 & 1 / 6 & 1 / 5 & 4 & 1 & 1 / 4 & 1 / 3 \\
1 / 6 & 1 & 1 / 7 & 1 / 7 & 1 / 6 & 1 / 3 & 1 / 3 & 1 / 6 & 1 / 7 \\
5 & 7 & 1 & 1 / 2 & 1 & 5 & 5 & 2 & 2 \\
6 & 7 & 2 & 1 & 1 & 7 & 6 & 2 & 5 \\
5 & 6 & 1 & 1 & 1 & 5 & 4 & 1 & 1 \\
1 / 4 & 3 & 1 / 5 & 1 / 7 & 1 / 5 & 1 & 1 / 4 & 1 / 6 & 1 / 6 \\
1 & 3 & 1 / 5 & 1 / 6 & 1 / 4 & 4 & 1 & 1 / 5 & 1 / 3 \\
4 & 6 & 1 / 2 & 1 / 2 & 1 & 1 / 6 & 5 & 1 & 2 \\
3 & 7 & 1 / 2 & 1 / 5 & 1 & 6 & 3 & 1 / 2 & 1
\end{array}\right] \\
& S C_{D M 3}=\left[\begin{array}{ccccccccc}
1 & 0.8 & 0.8 & 0.9 & 0.9 & 0.6 & 0.6 & 0.7 & 0.2 \\
0.8 & 1 & 0.8 & 0.9 & 0.9 & 0.7 & 0.7 & 0.8 & 0.2 \\
0.8 & 0.8 & 1 & 0.7 & 0.8 & 0.7 & 0.5 & 0.5 & 0.5 \\
0.9 & 0.9 & 0.7 & 1 & 0.9 & 0.8 & 0.8 & 0.9 & 0.9 \\
0.9 & 0.9 & 0.8 & 0.9 & 1 & 0.7 & 0.7 & 0.7 & 0.9 \\
0.6 & 0.7 & 0.7 & 0.8 & 0.7 & 1 & 0.8 & 0.8 & 0.8 \\
0.6 & 0.7 & 0.5 & 0.8 & 0.7 & 0.8 & 1 & 0.5 & 0.5 \\
0.7 & 0.8 & 0.5 & 0.9 & 0.7 & 0.8 & 0.5 & 1 & 0.6 \\
0.2 & 0.2 & 0.5 & 0.9 & 0.9 & 0.8 & 0.5 & 0.6 & 1
\end{array}\right]
\end{aligned}
$$

From the crisp AHP comparison matrices and their associated certainty matrices, the triangular neutrosophic weights resulting from the judgements of each DM for each criterion are evaluated following the methodological steps presented in Figure 1. The results are presented in Table 10.

\begin{tabular}{lccc}
\hline \multicolumn{1}{c}{ Criterion } & Decision Maker 1 & Decision Maker 2 & Decision Maker 3 \\
\hline C1-Construction costs & $\langle(0.01,0.02,0.07) ;$ & $\langle(0.06,0.13,0.34) ;$ & $\langle(0.02,0.05,0.15) ;$ \\
& $0.68,0.35,0.67\rangle$ & $0.86,0.26,0.86\rangle$ & $0.74,0.33,0.55\rangle$ \\
C2-Service life costs & $\langle(0.02,0.05,0.24) ;$ & $\langle(0.03,0.07,0.27) ;$ & $\langle(0.01,0.02,0.05) ;$ \\
C3-Damage to human & $0.68,0.32,0.67\rangle$ & $0.86,0.34,0.86\rangle$ & $0.74,0.30,0.55\rangle$ \\
& $\langle(0.07,0.21,0.60) ;$ & $\langle(0.06,0.20,0.63) ;$ & $\langle(0.05,0.18,0.56) ;$ \\
health & $0.68,0.28,0.67\rangle$ & $0.86,0.40,0.86\rangle$ & $0.74,0.32,0.55\rangle$ \\
& & & \\
C4-Damage to ecosystem & $\langle(0.07,0.23,0.66) ;$ & $\langle(0.06,0.19,0.55) ;$ & $\langle(0.10,0.25,0.59) ;$ \\
C5-Damage to resource & $0.68,0.38,0.67\rangle$ & $0.86,0.33,0.86\rangle$ & $0.74,0.14,0.55\rangle$ \\
& $\langle(0.07,0.25,0.72) ;$ & $\langle(0.11,0.30,0.71) ;$ & $\langle(0.06,0.16,0.46) ;$ \\
availability & $0.68,0.39,0.67\rangle$ & $0.86,0.31,0.86\rangle$ & $0.74,0.17,0.55\rangle$ \\
C6-Workers & & & \\
C7-Regional economic & $\langle(0.02,0.07,0.36) ;$ & $\langle(0.01,0.02,0.07) ;$ & $\langle(0.01,0.02,0.06) ;$ \\
& $0.68,0.44,0.67\rangle$ & $0.86,0.28,0.86\rangle$ & $0.74,0.24,0.55\rangle$ \\
development & $0.68,0.38,0.67\rangle$ & $0.86,0.24,0.86\rangle$ & $0.74,0.34,0.55\rangle$ \\
& & & \\
C8-Users & $\langle(0.02,0.07,0.23) ;$ & $\langle(0.01,0.05,0.14) ;$ & $\langle(0.05,0.15,0.49) ;$ \\
& $0.68,0.38,0.67\rangle$ & $0.86,0.32,0.86\rangle$ & $0.74,0.30,0.55\rangle$ \\
C9-Public opinion & $\langle(0.01,0.07,0.26) ;$ & $\langle(0.01,0.03,0.07) ;$ & $\langle(0.03,0.11,0.38) ;$ \\
& $0.68,0.51,0.67\rangle$ & $0.86,0.18,0.86\rangle$ & $0.74,0.46,0.55\rangle$ \\
\hline Table 10. Triangular neutrosophic weights according to each expert’s judgements
\end{tabular}

To evaluate the relevance of each DM in the sustainability assessment, the credibility $\delta$, indeterminacy $\theta$ and incoherency $\varepsilon$ parameters of each of them shall be quantified according to the methodology proposed in Section 2.2.3. Table 11 presents the 
profile characterization of each expert, as well as their associated assessment relevance $\phi$.

\begin{tabular}{lccc}
\hline \multicolumn{1}{c}{ Expert's profile characterisation } & Decision & Decision & Decision \\
& Maker 1 & Maker 2 & Maker 3 \\
\hline Years of professional experience & 5 & 19 & 15 \\
Specific knowledge in structural design & 0.6 & 1 & 0.8 \\
Specific knowledge in environmental projects assessment & 1 & 0.4 & 0.4 \\
Specific knowledge in social projects assessment & 0.8 & 0.8 & 0.6 \\
Specific knowledge in economic projects assessment & 0.6 & 1 & 0.718 \\
Expert's credibility $\delta$ & 0.653 & 0.84 & 0.741 \\
Expert's mean self confidence & 0.657 & 0.721 & 0.259 \\
Expert's mean indeterminacy $\theta$ & 0.343 & 0.279 & 0.059 \\
Comparison matrix consistency ratio & 0.072 & 0.096 & 0.595 \\
Expert's incoherency $\varepsilon$ & 0.722 & 0.959 & 0.277 \\
\hline
\end{tabular}

The individual neutrosophic weights resulting from the judgements of each DM are then aggregated considering the particular expert's assessment relevance following the described aggregation methodology. Figure 3 shows the resulting fuzzy weights after the deneutrosophication process of the aggregated weights. Finally, Figure 3 also presents the crisp weight of each criterion after applying the defuzzification method proposed by Chu (2002) for generalized fuzzy numbers. 

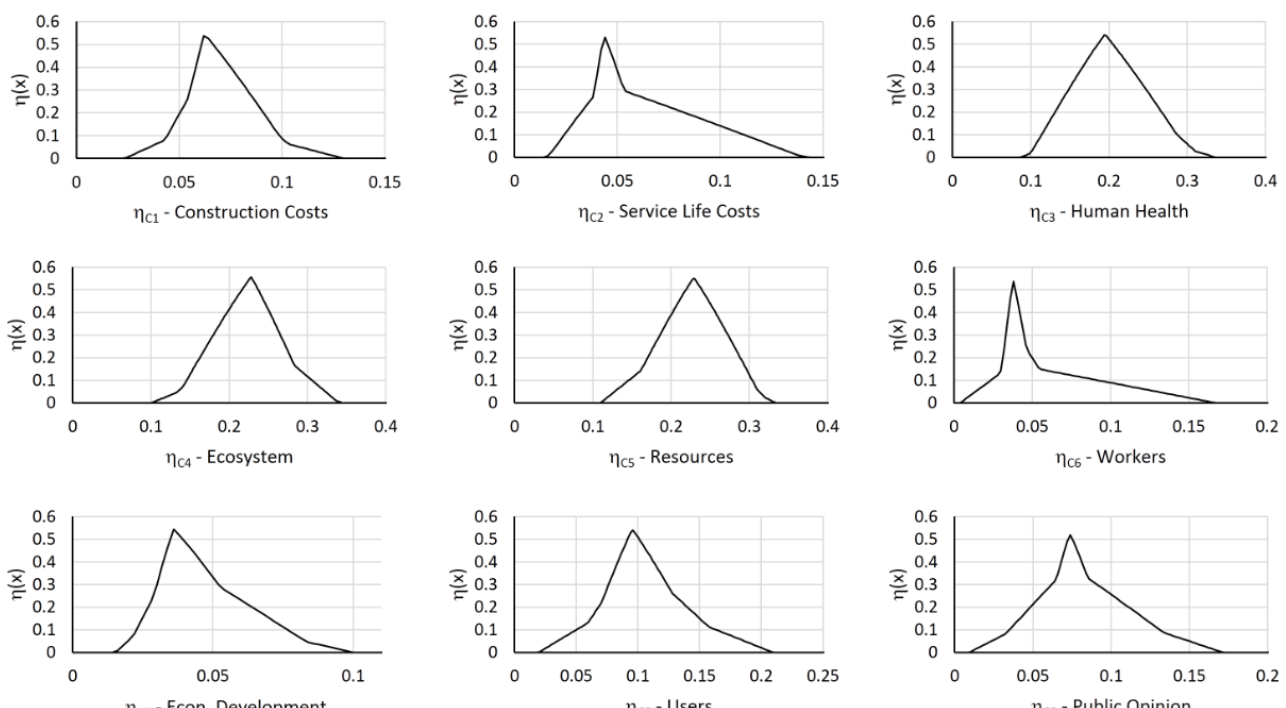

Resulting crips weights after defuzzification:

\begin{tabular}{|l|l|l|l|l|l|l|l|l|}
\hline$W_{\mathrm{C} 1}^{*}$ & $W_{\mathrm{C} 2}^{*}$ & $W_{\mathrm{C} 3}^{*}$ & $W_{\mathrm{C} 4}^{*}$ & $W_{\mathrm{C} 5}^{*}$ & $W_{\mathrm{C} 6}^{*}$ & $W_{\mathrm{C} 7}^{*}$ & $W_{\mathrm{C} 8}^{*}$ & $W_{\mathrm{C} 9}^{*}$ \\
\hline 0.061 & 0.045 & 0.188 & 0.225 & 0.224 & 0.039 & 0.036 & 0.0930 & 0.089 \\
\hline
\end{tabular}

Figure 3. Aggregated weights deneutrosophication results and defuzzified crisp weights

\subsection{LCCA results}

Here, the life cycle economic impacts of each design alternative are analysed, namely the construction and the discounted maintenance costs. It shall be noted that, for the good of the analysis, the results shown here consist in the aggregation of both criteria into a single economic score considering the crisp weights obtained above. Figure 4 shows the results for the particular maintenance intervals that lead to the lowest life cycle costs for each option. 


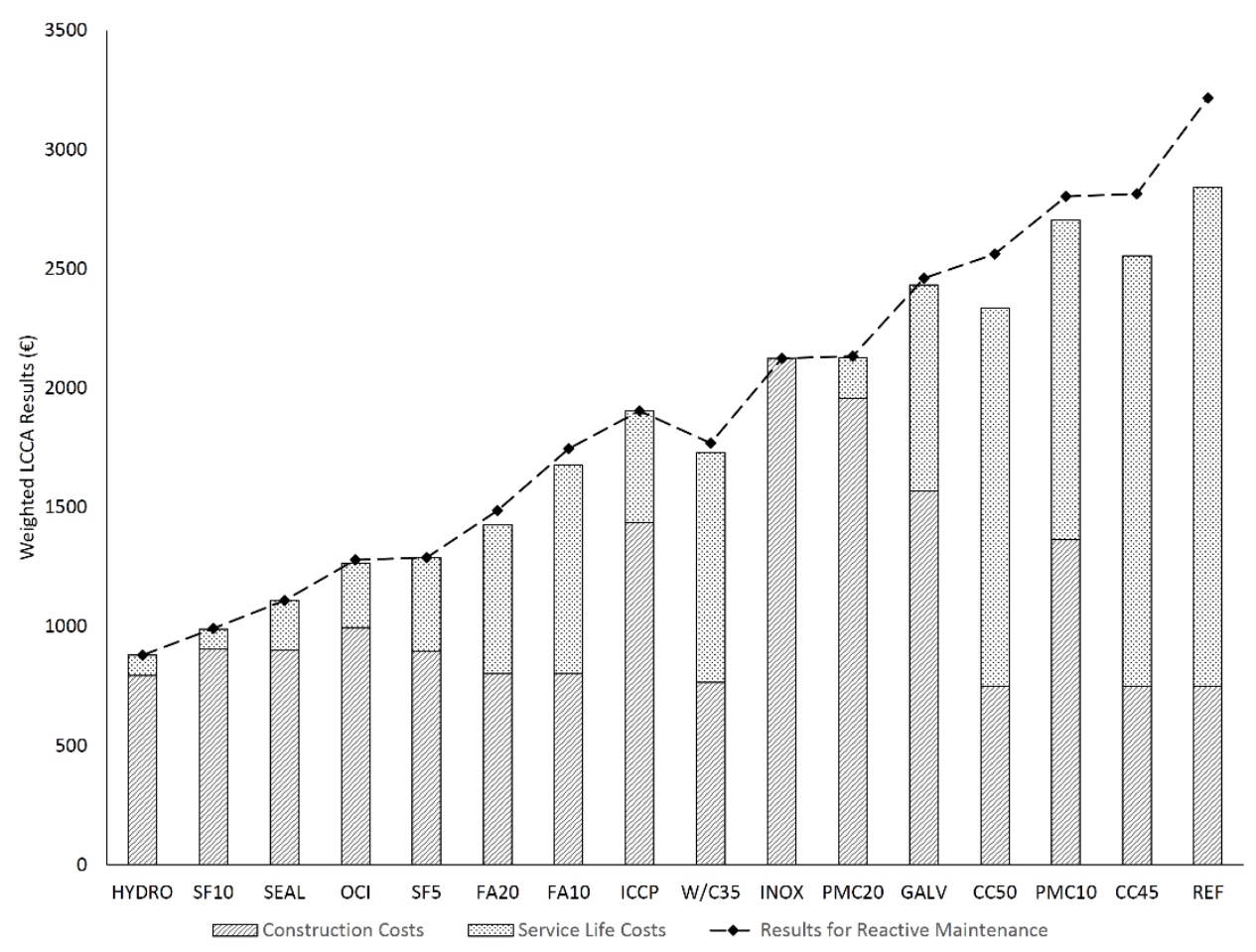

Figure 4. Economic life cycle assessment results

From the results, it is derived that the design that leads to the greatest economic impact is the baseline option (REF). It can be observed that in the case of those designs that incur the highest costs of the life cycle (REF, GALV, CC50, CC45, PMC10), the impact of the maintenance phase is quite significant, being in some cases up to 3.8 times greater than the construction costs (REF, CC45, CC50). But for the case of GALV, such results shall be explained by the fact that alternatives REF, CC45, CC50 and PMC10 are present worst durability performance. This dependence on the durability and the resulting life cycle costs was reported by García-Segura et al. (2017). However, it is observed that solutions with very low maintenance costs, such as INOX or PMC20 do not necessarily lead to the best economic performances, as they require significant construction costs.

Here, alternatives based on surface treatments (HYDRO and SEAL), and the design option based on silica fume addition SF10, have resulted in the lowest life cycle costs. Their economic scores range from $30.9 \%$ to $39.0 \%$ of the weighted economic impact associated to the baseline design. It is interesting to note that, contrarily to what 
is expected for such good economic results, the surface treatments require almost the greatest maintenance, at least every 5 years. However, the reduced construction costs, together with the low repair costs, explain the obtained competitive performance of these options. On the other hand, the good performance of SF10 relies on its low construction costs, as well as on the great durability of this type of concrete, as previously reported by Navarro et al. (2018a, 2019).

Figure 4 includes the LCCA results when reactive maintenance is assumed. Here, the differences between preventive and reactive maintenance strategies are not greater than $13 \%$ in the worst case (alternative REF). Alternatives with long spanning maintenance intervals, or those with very competitive maintenance costs, such as options based on surface treatments, show very slight differences with respect to preventive maintenance.

\section{3. $L C A$ results}

Figure 5 shows the results regarding the three environmental categories considered in the present assessment. Only the results of the best maintenance strategy for each option are shown. Again, the presented results are aggregated according to the crisp weights resulting from the neutrosophic AHP exposed above. Surface treatments and the silica fume option provide the best environmental performance. This agrees with Petcherdchoo (2015), who already reported that surface treatments are much more preferable from an environmental point of view than other designs in which the concrete cover has to be replaced periodically. This is due to the machinery with lower energy demand involved in the re-application of surface treatments. In addition, the design based on cathodic protection has also yielded a very good environmental response. These four design options have resulted in life cycle environmental impacts that range from $24.2 \%$ to $31.1 \%$ of the impact of the reference design. On the contrary, the worst environmental 
performances are those of the baseline design and the option based on stainless steel reinforcement. Such result confirms the relevant environmental burdens associated with the use of stainless steel in concrete reported by Mistry, Koffler, \& Wong (2016).

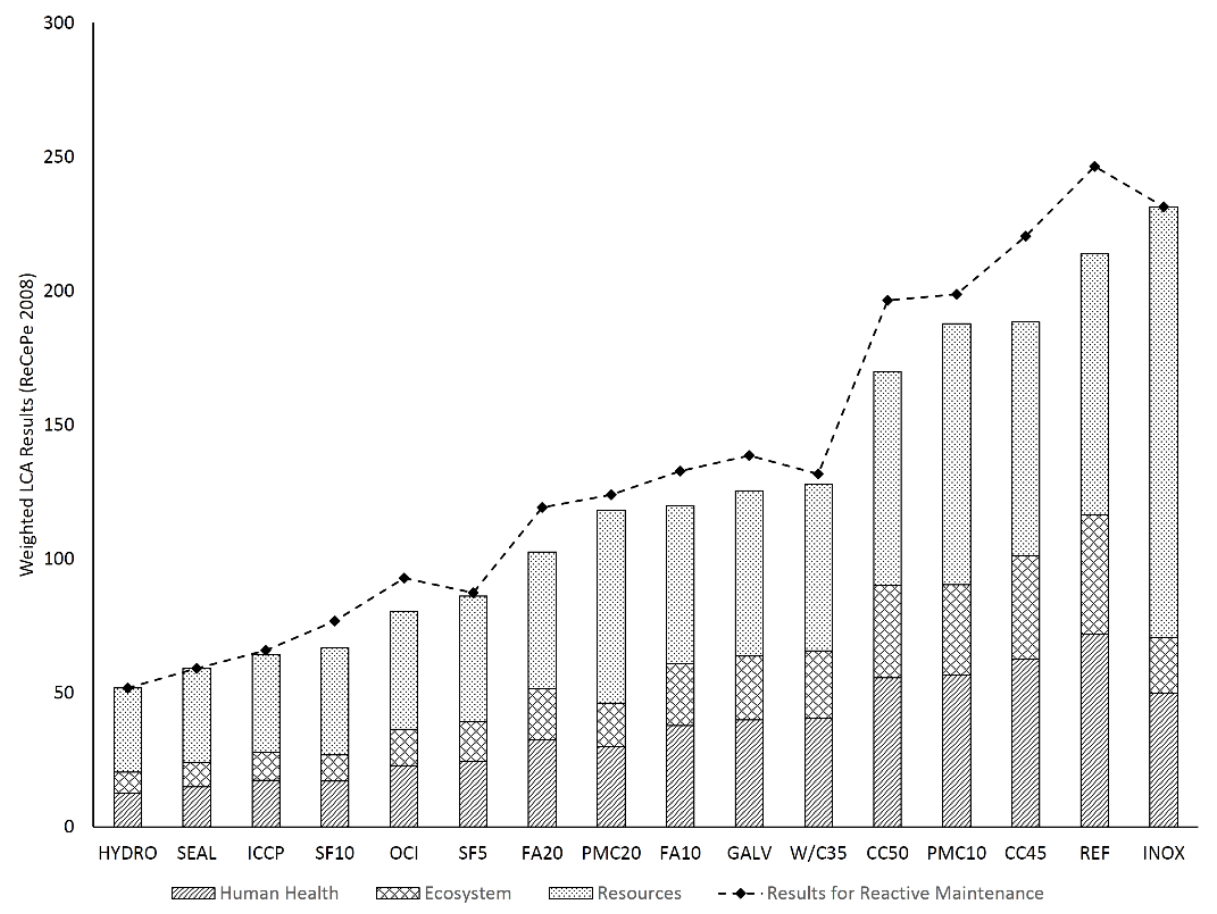

Figure 5. Environmental life cycle assessment results

Figure 5 includes LCA scores for each design alternative considering reactive maintenance strategies. Here, reactive maintenance may lead to environmental impacts up to $17 \%$ greater than those of a properly chosen preventive strategy. Such is the case of design options CC45, FA20, OCI or REF.

\subsection{SLCA results}

Figure 6 shows the social life cycle impact criteria of each design aggregated according to the obtained AHP weights. According to the resulting social scores, alternatives INOX, SF10 and PMC20 are by far the most preferable options. It shall be noted that these are alternatives with very low maintenance requirements due to their high durability. In consequence, the negative impacts on the local community and infrastructure users derived from maintenance works are reduced to nearly zero. In view of the resulting 
weights derived from the judgements of the panel of experts, these two stakeholders are almost three times more relevant from the point of view of sustainability than the workers or the regional economies. Therefore, those alternatives with greater maintenance demands that could be more beneficial to workers or could generate more economic flows are prejudiced against those that clearly benefit the users or the public opinion by reducing maintenance needs (Navarro et al., 2018b). Alternatives INOX, SF10 and PMC20 show social scores that are 5.62, 5.38 and 4.97 times higher than those of the reference design, respectively. In social terms, the option that performs the worst is the baseline design.

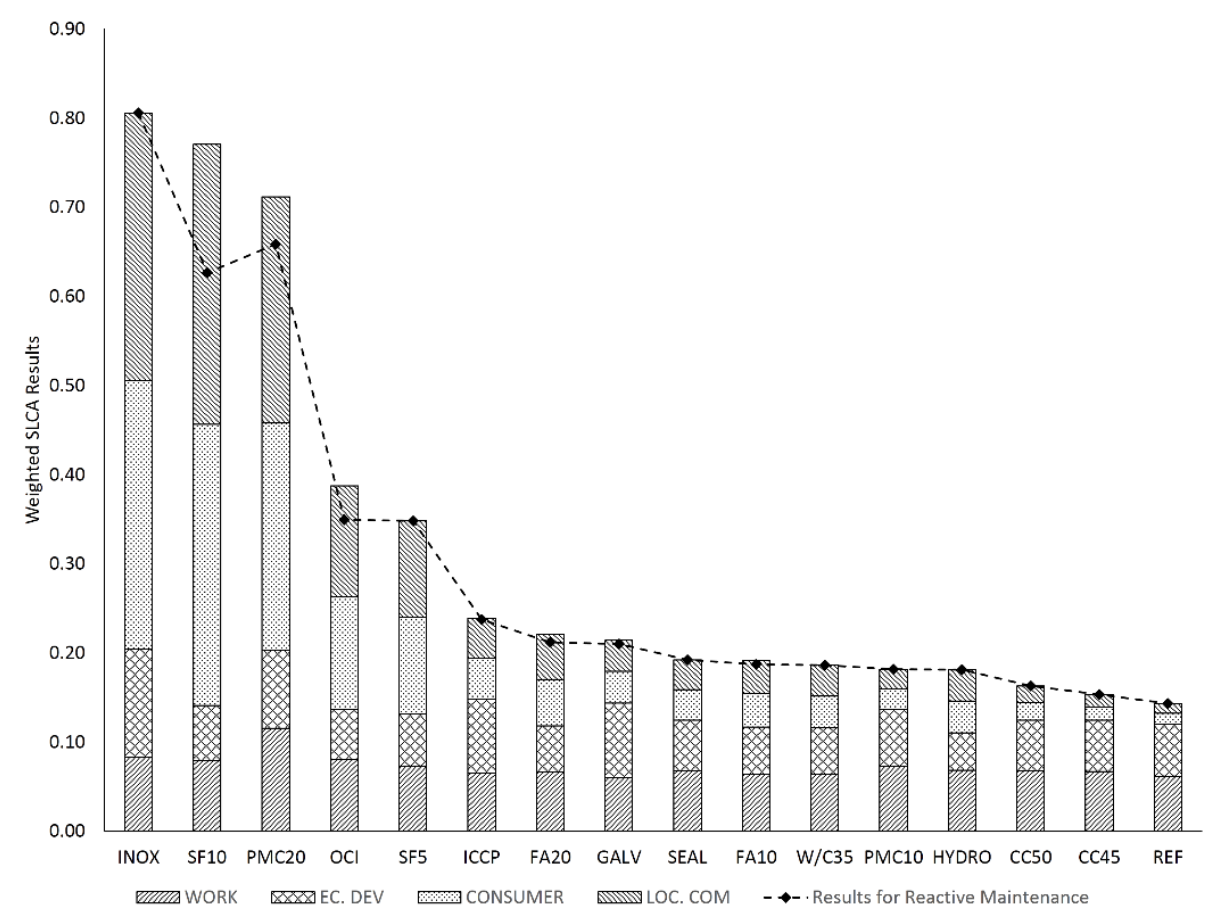

Figure 6. Social life cycle assessment results

Figure 6 includes the social scores of each alternative if reactive maintenance strategies are applied. It is observed that the greatest differences are obtained for those solutions with the greatest durability performances, such as SF10, OCI or PMC20. In those cases, the social performance with respect to preventive maintenance is reduced up to $14 \%, 5.3 \%$ and $3.8 \%$ respectively if reactive maintenance is chosen. 


\subsection{Sustainability results}

On the basis of the crisp weights obtained in Figure 3, the conventional TOPSIS technique is applied to aggregate the 9 different impact categories into a single sustainability score for each of the design options to be compared. Figure 7 shows the results for each design alternative, considering in each case the maintenance interval that leads to the highest score.

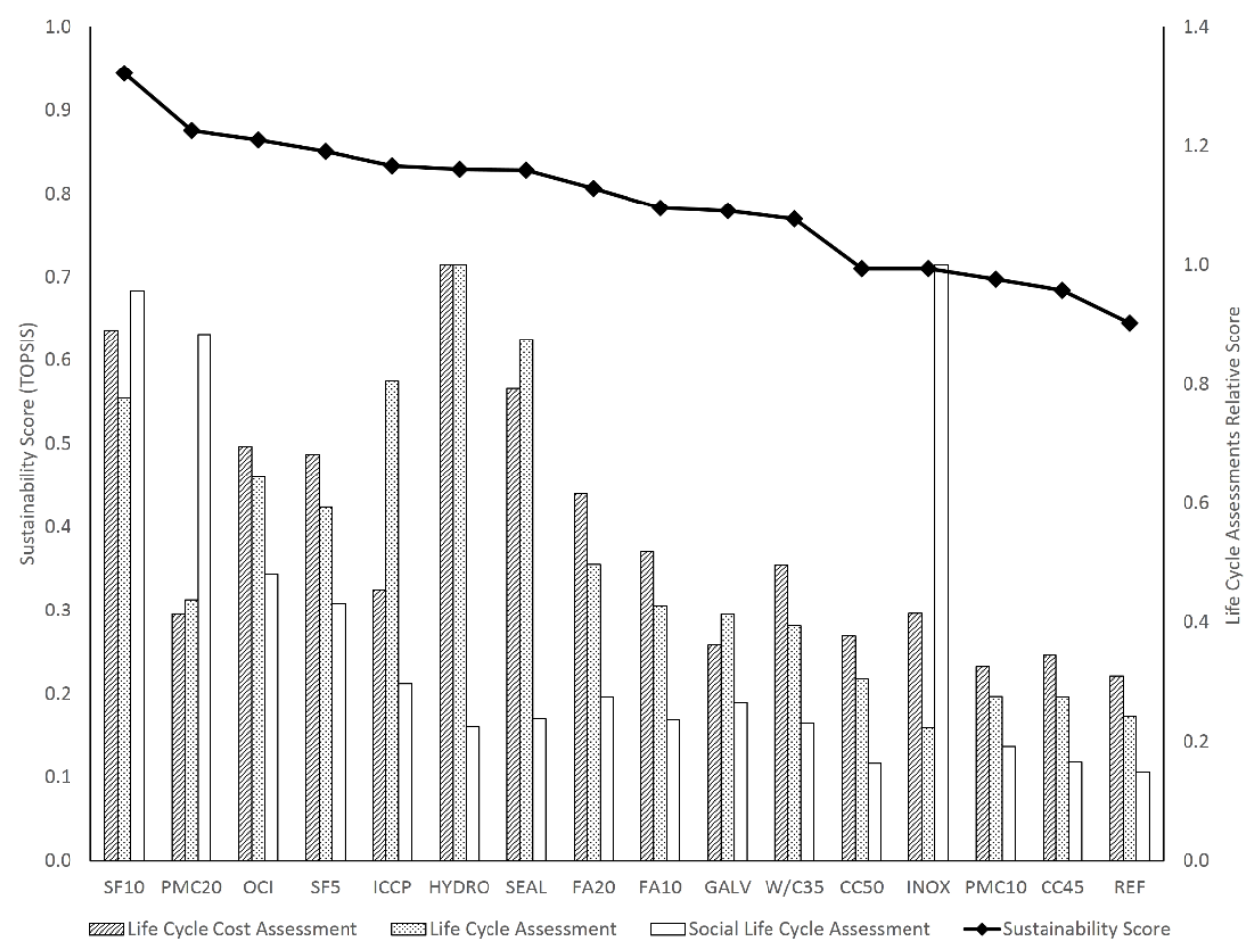

Figure 7. Sustainability assessment results

In addition, each alternative's economic, environmental and social scores obtained for its respective optimum interval are also presented as a fraction of the best obtained score in the particular field under assessment. The design alternative that has resulted to perform the best from a sustainability perspective is SF10, with an overall score of $94.4 \%$. In economic terms, although the construction costs of this design are greater than those of the baseline design, this solution incurs in almost negligible maintenance costs due to its 
high durability. Such reduced maintenance demand results in less negative affection to users and local community during the life cycle of the structure. In addition, the partial substitution of cement by silica fume allows for reduced cement production volumes, as well as the recycling of this industry by-product. On the contrary, the worst alternative has resulted to be the baseline option, scoring only $64.5 \%$. Reactive maintenance can reduce the sustainability score up to an additional $8 \%$ in the case of the baseline design or CC45. It is worth noting that alternatives HYDRO and INOX, which have resulted in the best LCCA, LCA and SLCA scores, have resulted to perform not significantly in the final sustainability assessment. In contrast, solutions that did not stand out from the rest in those individual evaluations, have resulted to perform brilliantly when aggregated into a sustainability score. This has happened with the alternatives PMC20, OCI or SF5, with sustainability scores of $87.5 \%, 86.4 \%$ and $85.1 \%$, respectively. In consequence, it is derived that those designs that perform best in any of the three pillars of sustainability independently, are not necessarily those that will perform best from a sustainability point of view.

\section{Conclusions}

This study evaluates the sustainability of 16 different design options for a prestressed concrete bridge deck exposed to an aggressive coastal environment. The life cycle economic, environmental and social impacts of each design alternative have been evaluated on the basis of the same functional unit and product system definition. The comparison of the sustainability associated with each design has been performed using the TOPSIS technique, so as to include the different impact categories in the final assessment. For the determination of the particular relevance of each criterion, a group AHP has been applied. However, given the conflicting nature of the sustainability criteria, the AHP pairwise comparisons are often complex and uncertain. In order to capture the 
inner sources of uncertainty in the judgements emitted by DM, AHP has been applied on the basis of the recently formulated neutrosophic logic, defined as a generalization of the fuzzy and intuitionistic logic.

Methodological gaps have been detected in the neutrosophic approach to the AHP technique. The present paper proposes an extension of the fuzzy method suggested by Enea and Piazza (2004) to deal with neutrosophic environments. In addition, the deneutrosophication method proposed by Sodenkamp et al. (2018) for single-valued neutrosophic numbers has been successfully adapted to handle with multi-valued neutrosophic numbers defined by general membership functions.

The proposed method is characterised by its ease of use for the decision makers, as they are only required to complete a comparison matrix as if it was a conventional AHP process. They are required to additionally express the certainty that they have when providing their judgements. The application of the proposed method results in crisp weights, that can directly be used with conventional MCDM techniques.

Under the assumptions adopted in the particular case study evaluated in the present paper, following specific conclusions are drawn:

- From the consultation with the panel of experts, environmental aspects have resulted to be the most relevant when assessing sustainability. In particular, damage to the ecosystem and depletion of natural resources have been considered of greater importance in comparison with the rest of the sustainability criteria. Weights of $22.5 \%$ and $22.4 \%$ have been assigned to those two criteria, respectively.

- With regards to social criteria, the effect on an infrastructure's life cycle on its users and on the public opinion of the local community has resulted to be three times more relevant than the effects on the mobilised working force and on the 
economic regional development resulting from the different construction and maintenance works. At last, construction and maintenance costs have been regarded as almost equally important from the point of view of the sustainability of an infrastructure.

- The use of concrete mixes where the cement is partially replaced by silica fume has resulted to provide the best life cycle response from the perspective of sustainability. Designing concrete structures exposed to chloride-laden environments with silica fume concretes results in highly durable solutions, with reduced environmental and economic impacts during its service life. This low maintenance demanding solution provides one of the best options from the social point of view, reducing to the minimum the negative effects on the local communities and on the infrastructure users. Design SF10 has resulted in a sustainability score $46.3 \%$ higher than that of the baseline design.

- Designs based on periodically reapplied surface treatments provide a highly desirable solution in economic and environmental terms due to the reduced costs and energy demands of their associated maintenance works. Their short durability makes them perform very poorly when considering the social dimension.

- When it comes to the evaluation of sustainability, designs that have provided the best results in the economic or environmental field individually have been overtaken by options with more balanced effects in all three dimensions of sustainability. In view of the obtained results, it is a matter of course that an adequate sustainable design of infrastructures should consider the three dimensions of sustainability simultaneously.

\section{Acknowledgements:}


The authors acknowledge the financial support of the Spanish Ministry of Economy and Competitiveness, along with FEDER funding (Project: BIA2017-85098-R).

\section{References:}

Atanassov, K. (1986). Intuitionistic Fuzzy Sets. Fuzzy Sets and Systems 20, 87-96.

Abdel-Basset, M., Manogaran, G., Mohamed, M., \& Chilamkurti, N. (2018) Three-way decisions based on neutrosophic sets and AHP-QFD framework for supplier selection problem. Future Generation Computer Systems, 89, 19-30.

Abdullah, L., \& Najib, L. (2016). Sustainable energy planning decision using the intuitionistic fuzzy analytic hierarchy process: choosing energy technology in Malaysia. International Journal of Sustainable Energy, 35(4), 360-377.

Ali, M., Aslam, M. S., \& Mirza, M. S. (2016). A sustainability assessment framework for bridges - a case study: Victoria and Champlain Bridges, Montreal. Structure and Infrastructure Engineering, 12(11), 1381-1394.

Allacker, A. (2012). Environmental and economic optimisation of the floor on grade in residential buildings. International Journal of Life Impact Assessment, 17, 813827.

Barone, G., \& Frangopol, D. (2014). Life-Cycle Maintenance of Deteriorating Structures by Multi-Objective Optimization Involving Reliability, Risk, Availability, Hazard and Cost. Structural Safety, 48, 40-50.

Biswas, P., Pramanik, S., Giri, B. (2016). TOPSIS method for multi-attribute group decision-making under single-valued neutrosophic environment. Neural Computing and Applications, 27(3), 727-737.

Bolturk, E., \& Kahraman, C. (2018). A novel interval-valued neutrosophic AHP with cosine similarity measure. Soft Computing, 22(15), 4941-4958.

Buckley, J. J. (1985). Fuzzy hierarchical analysis. Fuzzy Sets and Systems, 17(3), 233247.

Bykzkan, G., \& Ger, F. (2017) Application of a new combined intuitionistic fuzzy MCDM approach based on axiomatic design methodology for the supplier selection problem. Applied Soft Computing, 52, 1222-1238.

Cebeci, U. (2009). Fuzzy AHP-based decision support system for selecting ERP systems in textile industry by using balanced scorecard. Expert Systems with Applications, $36,8900-8909$.

Chen, C., Habert, G., Bouzidi, Y., Jullien, A., \& Ventura, A. (2010). LCA allocation procedure used as an incitative method for waste recycling: an application to 
mineral additions in concrete. Resources, Conservation and Recycling, 54(12), $1231-1240$.

Chu, T., \& Tao, C. (2002). Ranking fuzzy numbers with an area between the centroid point and original point. Computers \& Mathematics with Applications, 43(1), 111117.

Cope, A., Bai, Q., Samdariya, A., \& Labi, S. (2013). Assessing the efficacy of stainless steel for bridge deck reinforcement under uncertainty using Monte Carlo simulation. Structure and Infrastructure Engineering, 9.

De la Fuente, A., Pons, O., Josa, A., \& Aguado, A. (2016). Multi-criteria decision making in the sustainability assessment of sewerage pipe systems. Journal of Cleaner Production, 112, $4762-4770$.

Deli, I., \& Şubaş, Y. (2017). A ranking method of single valued neutrosophic numbers and its applications to multi-attribute decision making problems. International Journal of Machine Learning and Cybernetics, 8(4), 1309-1322.

Dezert, J. (2002). Open questions in neutrosophic inferences. Multiple-Valued Logic, $8(3), 439-472$.

Dong, Y., Zhang, G., Hong, W., \& Xu, Y. (2010). Consensus models for AHP group decision making under row geometric mean prioritization method. Decision Support Systems, 49(3), 281-289.

Dubois, D. (2011). The role of fuzzy sets in decision sciences: Old techniques and new directions. Fuzzy Sets and Systems, 184(1), 3-28.

Enea, M., \& Piazza, T. (2004). Project selection by constrained fuzzy AHP. Fuzzy Optimization and Decision Making, 3(1), 39-62.

Eamon, C.D., Jensen, E.A., Grace, N.F., \& Shi, X. (2012). Life-cycle cost analysis of alternative reinforcement materials for bridge superstructures considering cost and maintenance uncertainties. Journal of Materials in Civil Engineering, 24, $373-380$.

Fib. Fib Bulletin 34. (2006). Model Code for Service Life Design. Lausanne: Fib.

Fomento. (2000). Obras de paso de nueva construcción: conceptos generales. Madrid, Spain: Ministerio de Fomento.

Fomento. (2008). EHE-08 Instrucción del Hormigón Estructural. Madrid, Spain: Ministerio de Fomento. 
García-Segura, T., \& Yepes, V. (2016). Multiobjective optimization of post-tensioned concrete box-girder road bridges considering cost, $\mathrm{CO} 2$ emissions, and safety. Engineering Structures, 125, 325-336.

García-Segura, T., Yepes, V., Frangopol, D., \& Yang, D. Y. (2017). Lifetime Reliability based Optimization of Post-Tensioned Box-Girder Bridges. Engineering Structures, 145, 381-391.

García-Segura, T., Penadés-Plà, V., \& Yepes, V. (2018). Sustainable bridge design by metamodel-assisted multi-objective optimization and decision-making under uncertainty. Journal of Cleaner Production, 202, 904-915.

Gervásio, H., \& Da Silva, L. (2012). A probabilistic decision-making approach for the sustainable assessment of infrastructures. Expert Systems with Applications, 39, 7121-7131.

Goedkoop, M., Heijungs, R., Huijbregts, M., De Schryver, A., Struijs, J., \& Van Zelm, R. (2009). ReCiPe 2008, A life cycle impact assessment method which comprises harmonised category indicators at the midpoint and the endpoint level. Netherlands: Ministerie van Volkshuisvesting.

Guzmán-Sánchez, S., Jato-Espino, D., Bombillo, i., \& Diaz-Sarachaga, J. (2018). Assessment of the contributions of different flat roof types to achieving sustainable development. Building and Environment, 141, 182-192.

Heravi, G., Fathi, M., \& Faeghi, S. (2017). Multi-criteria group decision-making method for optimal selection of sustainable industrial building options focused on petrochemical projects. Journal of Cleaner Production, 142, 2999-3013.

Invidiata, A., Lavagna, M., \& Ghisi, E. (2018). Selecting design strategies using multicriteria decision making to improve the sustainability of buildings. Building and Environment, 139, 58-68.

ISO (2006). Environmental Management: —Life Cycle Assessment- Principles and Framework. Geneva: International Standards Organization.

ISO (2015). General Principles on Reliability for Structures. Geneva: International Standards Organization.

Jakiel, P., \& Fabianowski, D. (2015) FAHP model used for assessment of highway RC bridge structural and technological arrangements. Expert Systems with Applications, 42, 4054-4061.

JCSS (2001). Probabilistic Model Code. Zurich: Joint Committee on Structural Safety. ISBN 978-3-909386-79-6. 
Kahraman, C., Cebi, S., Onar, S. C., \& Oztaysi, B. (2018). A novel trapezoidal intuitionistic fuzzy information axiom approach: An application to multicriteria landfill site selection. Engineering Applications of Artificial Intelligence, 67, 157172.

Kere, K., \& Huang, Q. (2019). Life-cycle cost comparison of corrosion management strategies for steel bridges. Journal of Bridge Engineering, 24.

Liang, R., Wang, J., \& Zhang, H. (2018). A multi-criteria decision-making method based on single-valued trapezoidal neutrosophic preference relations with complete weight information. Neural Computing and Applications, 30(11), 3383-3398.

Liu, P., \& Liu, Xi. (2018) The neutrosophic number generalized weighted power averaging operator and its application in multiple attribute group decision making. International Journal of Machine Learning and Cybernetics, 9(2), 347-358.

Martí, J. V., García-Segura, T., \& Yepes, V. (2016). Structural design of precastprestressed concrete U-beam road bridges based on embodied energy. Journal of Cleaner Production, 120, 231-240.

Martínez-Blanco, J., Lehmann, A., Muñoz, P., Antón, A., Traverso, M., Rieradevall, J., \& Finkbeiner, M. (2014). Application challenges for the social life cycle assessment of fertilizers within life cycle sustainability assessment. Journal of Cleaner Production, 69, 34-48.

Mistry, M., Koffler, C., \& Wong, S. (2016). LCA and LCC of the world's longest pier: a case study on nickel-containing stainless steel rebar. International Journal of Life Cycle Assessment, 21, 1637-1644.

Moazami, D., Behbahani, H., \& Muniandy, R. (2011). Pavement rehabilitation and maintenance prioritization of urban roads using fuzzy logic. Expert Systems with Applications, 38(10), 12869-12879.

Mosalam, K. M., Alibrandi, U., Lee, H., \& Armengou, J. (2018). Performance based engineering and multi-criteria decision analysis for sustainable and resilient building design. Structural Safety, 74, 1-13.

Navarro, I. J., Martí, J. V., \& Yepes, V. (2018a). Life Cycle Cost Assessment of Preventive Strategies Applied to Prestressed Concrete Bridges Exposed to Chlorides. Sustainability, 10(3), 845.

Navarro, I.J., Yepes, V., \& Martí, J.V. (2018b). Social life cycle assessment of concrete bridge decks exposed to aggressive environments. Environmental Impact Assessment Review, 72, 50-63. 
Navarro, I. J., Martí, J. V., \& Yepes, V. (2018c). Life cycle impact assessment of corrosion preventive designs applied to prestressed concrete bridge decks. Journal of Cleaner Production, 196, 698-713.

Navarro, I. J., Martí, J. V., \& Yepes, V. (2019). Reliability-based maintenance optimization of corrosion preventive designs under a life cycle perspective. Environmental Impact Assessment Review, 74, 23-34.

Nogueira, C. G., Leonel, E. D., \& Coda, H. B. (2012). Reliability algorithms applied to reinforced concrete structures durability assessment. Revista IBRACON de Estruturas e Materiais, 5(4), 440-450.

Pamucar, D., Badi, I., Sanja, K., \& Obradovic, R. (2018). A Novel Approach for the Selection of Power-Generation Technology Using a Linguistic Neutrosophic CODAS Method: A Case Study in Libya. Energies, 11(9), 2489.

Penadés-Plà, V., García-Segura, T., Martí, J. V., \& Yepes, V. (2016). A review of multicriteria decision making methods applied to the sustainable bridge design. Sustainability, 8(12), 1295.

Peng, J. J., Wang, J., \& Yang, W. (2017). A multi-valued neutrosophic qualitative flexible approach based on likelihood for multi-criteria decision-making problems. International Journal of Systems Science, 48(2), 425-435.

Petcherdchoo, A. (2015). Environmental impacts of combined repairs on marine concrete structures. Journal of Advanced Concrete Technology, 13, 205-213.

Prascevic, N., \& Prascevic, Z. (2017). Application of fuzzy AHP for ranking and selection of alternatives in construction project management. Journal of Civil Engineering and Management, 23(8), 1123-1135.

Pryn, M. R., Cornet, Y., \& Salling, K. B. (2015). Applying sustainability theory to transport infrastructure assessment using a multiplicative AHP decision support model. Transport, 30(3), 330-341.

Radwan, N., Senousy, M., \& Riad, A. (2016). Neutrosophic AHP Multi-Criteria Decision Making method applied on the selection of learning management system. International Journal of Advancements in Computing Technology, 8(5), 95-105.

Rashidi, M., Samali, B., \& Sharafi, P. (2016). A new model for bridge management: Part B: decision support system for remediation planning. Australian Journal of Civil Engineering, 14, 46 - 53.

Saaty, T. L. (1980). The Analytic Hierarchy Process. New York, NY: McGraw-Hill. 
Sabatino, S., Frangopol, D., \& Dong, Y. (2016). Life cycle utility-informed maintenance planning based on lifetime functions: optimum balancing of cost, failure consequences and performance benefit. Structure and Infrastructure Engineering, 12(7), 830-847.

Safi, M., Sundquist, H., \& Karoumi, R. (2015). Cost-efficient procurement of bridge infrastructures by incorporating life-cycle cost analysis with bridge management systems. Journal of Bridge Engineering, 20.

Sajedi, S., \& Huang, Q. (2019). Reliability-based life-cycle-cost comparison of different corrosion management strategies. Engineering Structures, 186, 52-63.

Sierra, L. A., Pellicer, E., \& Yepes, V. (2016). Social sustainability in the life cycle of chilean public infrastructure. Journal of Construction Engineering and Management, 142(5).

Sierra, L. A., Yepes, V., García-Segura, T., \& Pellicer, E. (2018). Bayesian network method for decision-making about the social sustainability of infrastructure projects. Journal of Cleaner Production, 176, 521-534.

Smarandache, F. (1999). A Unifying Field in Logics, Neutrosophy: NeutrosophicProbability, Set and Logic. Rehoboth, NM: American Research Press.

Sodenkamp, M. A., Tavana, M., \& Di Caprio, D. (2018). An aggregation method for solving group multi-criteria decision-making problems with single-valued neutrosophic sets. Applied Soft Computing, 71, 715-727.

Stewart, M. G., Estes, A. C., \& Frangopol, D. M. (2004). Bridge deck replacement for minimum expected cost under multiple reliability constraints. Journal of Structural Engineering, 130.

Swarr, T., Hunkeler, D., Klöpffer, W., Pesonen, H., Ciroth, A., Brent, A., \& Pagan, R. (2011). Environmental life-cycle costing: a code of practice. International Journal of Life Impact Assessment, 16, 389-391.

Tahmasebi, Y., \& Yazdandoost, F. (2018). An integrated framework to evaluate resilientsustainable urban drainage management plans using a combined-adaptive MCDM technique. Water Resources Management, 32, 2817-2835.

Tesfamariam, S., \& Sadiq, R. (2006). Risk-based environmental decision-making fuzzy analytic hierarchy process (F-AHP). Stochastic Environmental Research and Risk Assessment, 21, 35-50. 
UNEP/SETAC. (2009). Guidelines for Social Life Cycle Assessment of Products. Paris, France: UNEPSETAC Life-Cycle Initiative.

Wang, Y. M., \& Elhag, T. M. (2006). On the normalization of interval and fuzzy weights. Fuzzy Sets and Systems, 157(18), 2456-2471.

WCED - World Commission on Environment and Development (1987). Our common future. Oxford University Press, Oxford. ISBN: 9780192820808.

Yang, Z., Shi, X., Creighton, A. T., \& Peterson, M. M. (2009). Effect of styrenebutadiene rubber latex on the chloride permeability and microstructure of Portland cement mortar. Construction and Building Materials, 23(6),2283-2290.

Ye, J. (2013). Multicriteria decision-making method using the correlation coefficient under single-value neutrosophic environment. International Journal of General Systems, 42(4), 386-394.

Ye, J. (2017). Subtraction and Division Operations of Simplified Neutrosophic Sets. Information, 8(2), 51-58.

Yepes, V., García-Segura, T., \& Moreno-Jiménez, J. (2015). A cognitive approach for the multi-objective optimization of RC structural problems. Archives of Civil and Mechanical Engineering, 15, 1024-1036.

Zadeh, L. (1965). Fuzzy Sets. Information and Control 8, 338-353.

Zadeh, L. (1973). Outline of a new approach to the analysis of complex systems and decision processes. IEEE Transactions on Systems, Man, and Cybernetics, 3, 28 44.

Zavadskas, E., Mardani, A., Turskis, Z., Jusoh, A., \& Nor, K. (2016). Development of TOPSIS method to solve complicated decision-making problems: An overview on developments from 2000 to 2015. International Journal of Information Technology \& Decision Making, 15. 